\title{
Una vida internacional marcada por y para la diplomacia. James Holger Blair un coetáneo de los grandes procesos de Chile y el mundo (1928-2014)*
}

\author{
An international life traced by and for diplomacy. James Holger-Blair, contemporary of \\ the great processes of Chile and the world (1928-2014)
}

\author{
Cristián Medina Valverde** \\ Erna Ulloa Castillo *** \\ Álvaro Sierra Rivas ${ }^{* * * *}$
}

\section{RESUMEN}

Se aborda el decurso vital y profesional del diplomático chileno James Holger Blair (1928-2014), a quién le correspondió realizar diversas tareas para el servicio exterior de Chile. Su labor se desarrolló en el contexto de la Guerra Fría y de su período inmediatamente posterior. El trabajo utiliza el enfoque de la nueva Historia Diplomática y se basa en fuentes primarias inéditas y cardinales del Archivo General Histórico del Ministerio de Relaciones Exteriores de Chile, específicamente el archivo James Holger Blair, archivo de las Naciones Unidas, archivo digital del presidente Patricio Aylwin, fuentes hemerográficas chilenas y alemanas, complementadas con fuentes secundarias de alta calidad académica que han tratado el contexto histórico internacional donde este agente de la diplomacia chilena se desenvolvió.

Palabras Claves: Chile - Ministerio de Relaciones Exteriores - Diplomacia - Embajador - James Holger

\section{ABSTRACT}

This paper deals with the life and professional career of the Chilean diplomat James Holger Blair (19282014), who performed various tasks for the Chilean foreign service. His duties took place in the context of the Cold War and its immediate aftermath. The work uses the approach of the new Diplomatic History and is based on unpublished and cardinal primary sources of the General Historical Archive of the Ministry of Foreign Affairs of Chile, specifically the James Holger B. archive, the United Nations archive, the digital archive of President Patricio Aylwin, Chilean and German newspaper sources, complemented with secondary sources of high academic quality that have comprehended with the international historical context where this agent of Chilean diplomacy was involved.

Keywords: Chile, Ministry of Foreign Affairs, Diplomacy, Ambassador, James Holger

\footnotetext{
* Proyecto ANID/FONDECYT Regular N¹170184, "Historia de las Relaciones Internacionales de Chile: "El Caso Honecker". Tensiones internacionales y conflictos internos en la post Guerra Fría. Chile 1988-1994.

** Doctor en Historia, Universidad Complutense de Madrid, Profesor Investigador, Instituto de Historia, Universidad San Sebastián, Chile. ORCID: https://orcid.org/0000-0002-3487-182X. Correo electrónico: cristian.medina@uss.cl.

*** Doctora en Historia, Universidad de Valladolid, Profesora Asociada, Departamento de Historia y Geografía, Universidad Católica de la Santísima Concepción, Chile. ORCID: https://orcid.org/0000-0001-6289-5389. Correo electrónico: eulloa@ucsc.cl.

**** Licenciado en Historia, Universidad Católica de la Santísima Concepción, Chile. ORCID: https://orcid.org/00000003-4924-2695.Correo electrónico: asierra@historia.ucsc.cl.
} 
Recibido: agosto 2020

Aceptado: marzo 2021

\title{
Introducción
}

\begin{abstract}
"La función del historiador no es ni amar el pasado ni emanciparse de él, sino dominarlo y comprenderlo, como clave para la comprensión del presente" ¿Qué es la Historia", E.H. Carr
\end{abstract}

En el desarrollo de la política exterior de un Estado es relevante conocer el trabajo diplomático que se realiza en función de los lineamientos establecidos en estos ámbitos ${ }^{1}$. El presente artículo se adentra en la labor que desarrolló para la diplomacia chilena y en diversos momentos claves para Chile, James Holger Blair².

Entre las muchas tareas en las que participó, algunas de ellas prácticamente desconocidas, estuvieron ser parte del equipo que le correspondió abrir la Embajada chilena en la Unión de Repúblicas Socialistas de la Unión Soviética (URSS) durante el gobierno de Eduardo Frei Montalva (1964-1970), y, posteriormente, en la República Democrática Alemana (RDA) durante el período de la Unidad Popular (1970-1973) ${ }^{3}$. En marzo de 1992, el presidente Patricio Aylwin lo designó como embajador especial en la URSS para negociar con Alemania y Rusia una salida al denominado "caso Honecker", en un momento en que Chile hacía su transición hacia la democracia y buscaba reinsertarse internacionalmente luego de los años de la dictadura militar (1973-1990), aun cuando efectivamente se mantuvo relaciones de asociatividad a nivel tanto de relaciones internacionales y de comercio con Japón, Corea del Sur y China ${ }^{4}$.

James Holger tuvo una intensa vida internacional, fue un gestor dinámico de la diplomacia y del servicio exterior chileno durante la segunda mitad del siglo XX y primeras años del siglo XXI, pese a ello es prácticamente un desconocido fuera de los círculos de la Cancillería y de los organismos internacionales ${ }^{5}$. El levantamiento bibliográfico reveló la ausencia de escritos sobre

\footnotetext{
1 Merle, Marcel. 1991. Sociología de las Relaciones Internacionales, Madrid, Aa. edición, Alianza; Truyol, Antonio. 1973. La teoría de las relaciones internacionales como sociología, Madrid, Ediciones Internacionales.

2 Revista Ayer (dossier). 2014. Los retos de la biografía, Madrid, Asociación de Historia Contemporánea, Madrid; Dosse, François. 2007. El arte de la biografía, México, Universidad Iberoamericana; Gallego, Henar y Bolufer, Mónica (ed). 2016. ¿YY ahora qué? Nuevos usos del género biográfico, Barcelona, Icaria.

${ }^{3}$ Gajardo, Gustavo; Medina, Cristian. 2019. "De la amistad a la Diplomacia. El reconocimiento Internacional del gobierno de la Unidad Popular a la República Democrática Alemana. 1971", Izquierdas, N 48, Santiago, pp. 44-63. ${ }_{4}^{4}$ Para mayor detalle remitimos a: Artaza, Mario; Ross, César (editores). 2012. La política exterior de Chile, 1990-2009. Del aislamiento a la integridad global, Santiago, Ril editores.

${ }^{5}$ Algunos trabajos recientes sobre diplomáticos chilenos, Ulloa, Erna; Medina Cristián. 2019. "Outline of a diplomatic leader in the international community: Hernán Santa Cruz and his works at the United Nations", Human Rights Quaterly, Maryland, p.41. Ross, César. 2014. "Hernán Santa Cruz: del pensamiento a la acción”, Horizontes
} 
su trayectoria diplomática en el marco de la Historia de las Relaciones Internacionales o de la Historia Diplomática de Chile.

Las distintas misiones encomendadas dentro de un sistema internacional bipolar (19471989/91) o de nuevo orden internacional, nutrieron su forma de actuar, de hacer diplomacia, y modelaron su comprensión sobre las relaciones internacionales.

El artículo tiene como objetivos investigar y revelar la figura de este diplomático estableciendo el alcance de sus distintas misiones para el servicio exterior de Chile. Las interrogantes en torno a las que se estructura el trabajo son: ¿Cuál es la relevancia que tiene James Holger dentro de la diplomacia chilena? ¿Cómo influyó el contexto histórico nacional y mundial en sus distintas misiones como diplomático?, y, ¿Cuál fue el momento durante la carrera profesional de Holger en que éste se consolidó dentro de la diplomacia chilena? Estas preguntas en conjunto con los objetivos nos llevan a plantear como hipótesis que James Holger fue una figura destacada no solo en la diplomacia chilena sino también para la Historia de las Relaciones Internacionales, siendo un testigo y gestor dinámico de primera línea en hitos trascendentales de la historia del siglo XX.

A nivel metodológico hemos privilegiado el método cualitativo inductivo utilizando como fuentes primarias documentos diplomáticos inéditos del Archivo General Histórico del Ministerio de Relaciones Exteriores (AGHMINREL), archivo de Naciones Unidas, archivo digital del presidente Patricio Aylwin, prensa del período y fuente oral por medio de una entrevista semiestructurada ${ }^{6}$. La consulta multi archivística se complementó con bibliografía secundaria, lo que permitió realizar una descripción y observación sistemática de la intensa trayectoria de James Holger Blair tanto al servicio de Chile como de la comunidad internacional.

\section{El camino a una vida diplomática}

La infancia y adolescencia de James Holger estuvo marcada por las labores profesionales de su padre, Immanuel Holger, un oficial de la Armada de Chile, que en 1927 se casó Mary Elizabeth Blair Kirkwood en Viña del Mar ${ }^{7}$. Al año siguiente, siendo agregado naval de la Embajada de

Latinoamericanos, Vol.1, №2, Recife, pp.79-92. Lagos, Jaime. 2008. Al servicio de Chile. Crónicas de un diplomático, Santiago, Ediciones Universidad Fines Terrae.

${ }^{6}$ Alia, Francisco. 2017. Técnicas de investigación para historiadores. Las fuentes de la historia, Madrid, Editorial Síntesis. Aróstegui, Julio. 1995. La investigación histórica. Teoría y Método, Barcelona, Crítica.

${ }^{7}$ Immanuel Holger Torres, fue hijo de Otto Olger y Ercilla Torres, nació el 1 de junio de 1893 en Valparaíso. Ingresó a la Escuela Naval en marzo de 1907, egresando como guardiamarina de $2^{\circ}$ clase. En 1937 fue nombrado subsecretario de Marina y en 1939, secretario general de la Armada. En 1941 fue designado edecán naval del presidente Pedro Aguirre Cerda. En 1942 asumió como agregado naval de la Embajada de Chile y jefe de la Misión Naval en Washington. En agosto de 1947 fue nombrado ministro del Interior por el presidente Gabriel Gonzáles Videla. El 7 de diciembre de 1948 ascendió a vicealmirante. En 1952 se le concedió el retiro de la Armada. Desde 1959 hasta 1961 fue Intendente de Concepción. Falleció el 2 de junio de 1963 en Santiago. Armada de Chile. 2009. Almirantes de la República de Chile. 1810-2010, tomo I, 1810-1952, Valparaíso, Museo Naval y Marítimo, pp. 312 313. 
Chile en Washington D. C. (Estados Unidos), nació el hijo único de la pareja, James Holger Blair, el 5 de enero de 1928. El trabajo de su padre dejó una impronta en su formación. En e fecto, el estar constantemente viajando y viviendo en diferentes países con motivo de las destinaciones profesionales de su progenitor, le otorgó la posibilidad ampliar su visión del mundo y de la cultura. Sus estudios primarios y secundarios los cursó entre Washington, Santiago y Valparaíso hasta llegar finalmente a Concepción, donde su padre fue asignado como Comandante en Jefe de la Segunda Zona Naval de Talcahuano ${ }^{8}$.

En cuanto a su educación universitaria, esta fue clave para su ingreso a la carrera diplomática. En 1948 egresó de la Escuela de Derecho de la Universidad de Chile, para luego continuar sus estudios en diversas universidades de los Estados Unidos. Fue alumno del Institute of Languages and Linguistics en Georgetown University, posteriormente realizó un posgrado en Relaciones Internacionales en la University of Virginia, y recibió también un diploma en Estudios Africanos. Luego ingresaría al Ministerio de Relaciones Exteriores (MINREL) de Chile, siendo en 1949 becado para estudiar en el Instituto de Estudios Políticos de la Universidad de París. Posteriormente, entre 1972 y 1976, completó un Doctorado en Historia en la Columbia University, de la ciudad de Nueva York. ${ }^{9}$.

Todos estos estudios fueron muy valiosos en su formación profesional como diplomático al proporcionarle una visión de los contextos mundiales, regionales y nacionales. Este punto es importante, puesto que, al momento de ingresar al servicio exterior, la sociedad internacional atravesaba por la segunda post guerra y luego vendría la Guerra Fría, etapa en el que Holger desarrolló la mayor parte de su carrera diplomática y, por último, la etapa de la temprana post Guerra Fría donde le tocó enfrentar las complejas negociaciones tripartitas del denominado "caso Honecker".

Sus estudios académicos le permitieron ser reconocido dentro de su círculo de amistades y profesional como un hombre de vasto conocimiento en distintas áreas, destacándose como alguien versado en Historia, Relaciones Internacionales, Política Internacional y Economía, así como en diversos movimientos políticos y sociales. Además, hablaba perfectamente inglés, francés, italiano, portugués, y poseía buen dominio de alemán y ruso ${ }^{10}$. Sin lugar a dudas estos atributos intelectuales le permitieron desarrollar funciones tanto en las embajadas chilenas en Estados Unidos, Alemania Federal, República Democrática Alemana (RDA) y en la Unión de

\footnotetext{
${ }^{8}$ Archivo General Histórico del Ministerio de Relaciones Exteriores de Chile (en adelante AGHMINREL), Fondo Histórico, EE. UU, Vol. 5672, № 747/62. Embajada chilena en Washington D.C, Estados Unidos, Estados Unidos. 18 de abril, 1960, p. 2.

9 Ídem.

${ }^{10}$ Entrevista a Jaime Carrasco realizada el 1 de octubre de 2019 en la ciudad de Chillán. Jaime Carrasco, fue amigo personal del matrimonio Blair Becerra y es gestor cultural de la Municipalidad de Chillán.
} 
Repúblicas Soviéticas (URSS), estos últimos países con sistema de partido único y economías centralmente planificadas, así como en los organismos internacionales en los que sirvió tareas.

El ingreso de James Holger al servicio exterior de Chile se resolvió por un concurso público al que postuló junto a otros 52 aspirantes en mayo de $1949^{11}$. Durante lo que fue su periodo formativo en el Ministerio de Relaciones Exteriores (MINREL), además de sus estudios de perfeccionamiento en el extranjero, realizó funciones en la división de economía y en la de política, ejerciendo también como asistente del traductor oficial del Ministerio ${ }^{12}$.

Parte importante de su vida diplomática se desarrolló durante el periodo de Guerra Fría, asumiendo tareas al interior de diversas embajadas chilenas y en organismos internacionales que mediaron en algunos de los conflictos de ese período. Así, por ejemplo, en junio de 1958 empezó a trabajar como representante alterno de Chile en el Consejo Económico y Social ante la Organización de Estados Americanos (OEA), periodo en que paralelamente ofició como asesor de la delegación chilena ante el Consejo de la OEA hasta $1960^{13}$.

Tras ello, su siguiente designación fue la de tercer secretario de la legación diplomática de la Embajada de Chile en Washington D.C., Estados Unidos, entre 1960 y $1964^{14}$. Son los años, como describe la historiadora Erika Pani, en que EE.UU. vivió tensiones y cambios en su política exterior dominada por el conflicto que sostenía con la URSS, rivalidad que no solo se visualizó en materias de política exterior sino que también permeó la política interna de los norteamericanos ${ }^{15}$. Durante ese período la Casa Blanca impulsó la Alianza Para el Progreso (1961), buscando fortalecer y ayudar económicamente a los países latinoamericanos como forma de contrarrestar el avance del comunismo en la región ${ }^{16}$. De igual modo, marcaría este periodo la denominada "crisis de los misiles", uno de los hechos que hizo escalar al máximo la tensión no solo entre estas dos potencias, sino que también al interior del Consejo de Seguridad de la ONU, en un momento en que Chile era miembro no permanente de este ${ }^{17}$.

\footnotetext{
${ }^{11}$ AGHMINREL, Fondo Histórico, EE. UU., Vol. 5672, № 747/62. Embajada chilena en Washington D.C, Estados Unidos, Estados Unidos. 18 de abril, 1960 p. 2. Lagos, Jaime. "James Holger", El Mercurio. Lunes 11 de agosto de 2014, Cartas al director, p. A2.

${ }^{12}$ AGHMINREL, Fondo Histórico, EE.UU., Vol. 5672, № 747/62. Embajada chilena en Washington D.C, Estados Unidos, Estados Unidos. 18 de abril, 1960, p. 2.

13 Ídem.

14 Ídem.

${ }^{15}$ Pani, Erika. 2016. Historia mínima de Estados Unidos de América, Madrid Turner Publicaciones, p. 217.

${ }^{16}$ Grant, Susan-Mary. 2014. Historia de Estados Unidos de América. Madrid, Akal Ediciones, pp. 432-433.

17 Sobre lo que fue el ingreso de Chile al Consejo de Seguridad para el bienio 1961-1962, remitimos a: Memorias de Ministerio de relaciones Exteriores de Chile, 1960. Primera parte, Departamento político, capítulo II, Organismos y Conferencias Internacionales, p.137. AGHMINREL, Fondo Organismos Internacionales, Organización de Naciones Unidas, "oficio confidencial N²3/2", delegación ante Naciones Unidas, Departamento Político, sesión 923, 9 enero 1961. Ulloa, Erna. 2013. Chile ante el Consejo de Seguridad de Naciones Unidas. Acción Diplomática y Opinión Pública 1952-2004. Tesis doctoral, Universidad de Valladolid, p.351.
} 
Es entonces bajo este escenario de tensión en materia de política internacional donde un joven James Holger inició sus primeras labores diplomáticas, recogiendo una valiosa experiencia profesional que terminará marcando su visión y carácter en dichas materias. Este bagaje será de mucha utilidad cuando sea destinado a la URSS, Alemania Federal, y posteriormente, a la República Democrática Alemana (RDA), escenarios relevantes durante el conflicto bipolar ${ }^{18}$.

\section{Misión diplomática en Moscú}

Luego de su misión diplomática en los Estados Unidos, Holger fue enviado a la URSS entre 1965 y $1968^{19}$, gracias a la solicitud de su amigo Máximo Pacheco, quien por entonces oficiaba como embajador de Chile en Moscú ${ }^{20}$. La política interna de la URSS vivía en esos momentos importantes cambios, Nikita Jruschov había sido destituido como primer secretario del Comité Central del Partido Comunista de la URSS y en su reemplazo asumió Leonid Brezhnev. Esto fue visto al interior de la URSS como el nacimiento de un periodo de desarrollo sostenido para la economía y la sociedad soviética ${ }^{21}$.

Por su parte, la política exterior soviética experimentó graves problemas con los países que conformaban el bloque del este. Charles Zorgbibe explica que Checoslovaquia vivía una renovación de su sistema político tras la dimisión forzada del antiguo estalinista Antonin Novotny, quien fue reemplazado por Alexander Dubcek en $1968^{22}$. Los nuevos dirigentes pretendían dar un giro al modelo centralizado de la URSS, lo que provocó la invasión soviética a Checoslovaquia el 21 de agosto de 1968, para interrumpir un proceso que ponía en peligro al conjunto del campo soviético ${ }^{23}$. Esta acción generó una serie de críticas, tanto de los países del Pacto de Varsovia como del mundo occidental, por lo tanto James Holger debió moverse diplomáticamente en momentos álgidos de la política mundial y de crisis internacionales.

Chile no tenía relaciones diplomáticas con la URSS desde 1947, y no fue hasta 1964 bajo el gobierno del democratacristiano Eduardo Frei Montalva que ambos países reanudaron sus relaciones diplomáticas ${ }^{24}$. El gobierno de Santiago designó entonces a Máximo Pacheco como

\footnotetext{
${ }^{18}$ Gajardo, Gustavo; Medina, Cristian. 2019. De la amistad a la Diplomacia, pp. 1468-1492.

${ }^{19}$ El Mercurio, "Holger, nuevo embajador en Moscú", lunes 9 de septiembre de 1992, p. C6.

20 Pacheco Máximo; Holger, James. 2009. Recuerdos de la Unión Soviética, Santiago, Editorial Andrés Bello, p. 9. El 12 de junio de 1965 fue la entrega de las cartas credenciales que acreditaron a Máximo Pacheco como Embajador de Chile ante la URSS.

${ }^{21}$ Service, Robert. 2000. Historia de Rusia en el siglo XX, Barcelona Editorial Crítica, pp. 353-355.

22 Secretario General del Partido Comunista de Checoslovaquia entre 1968-1969.

${ }^{23}$ Zorgbibe, Charles. 1997. Historia de las relaciones internacionales. Del sistema de Yalta a nuestros días, Madrid, Alianza Editorial, pp. 338-339. Medina, Cristián; Gajardo, Gustavo. 2017. "The fissures of the "curtain of steel" from Chile. Poland 1956", Almanaque histórico latinoamericano, Moscú, № 18, pp. 220-242.

${ }^{24}$ AGHMINREL, Fondo Países, Rusia, Vol. 198/ rus/1. Embajada de Chile en Moscú. 2 de abril, 1965, confidencial 1.
} 
embajador de Chile en la URSS ${ }^{25}$ y como primer secretario en esa legación diplomática a James Holger, quien llegó a Moscú el 22 de mayo de $1965^{26}$. Los agentes de la diplomacia chilena tuvieron la misión de construir vínculos con la URSS después de 17 años, tarea nada de sencilla que implicó saber dialogar con uno de los actores relevantes del sistema internacional del período.

Probablemente una de las ventajas para llevar a cabo esta tarea fue la buena opinión que tenía Andrei Gromyko del presidente Frei Montalva, por lo menos así lo graficó, en junio de 1965, el propio embajador Máximo Pacheco al canciller chileno tras una de las primeras reuniones sostenida junto a James Holger y Alberto Yoacham, con Gromyko. El embajador Pacheco manifestó que el líder soviético valoraba la política internacional de Frei Montalva y que la URSS deseaba la paz y apoyaba a todos los países que estuvieran buscando su autodeterminación política y económica. Gromyko estaba informado de las políticas progresistas que llevaba adelante el gobierno como: la reforma agraria, la nacionalización de cobre y la reforma educacional, incluso manifestó en dicho encuentro que estaba dispuesto a entregar una ayuda económica al gobierno chileno ${ }^{27}$.

Pero este no sería el único encuentro en que participaría Holger durante su misión en Moscú. También asistió a una reunión en el Kremlin con Alekséi Kosyguin, con el fin de exponer ante las autoridades soviéticas cuáles eran las políticas impulsadas por el presidente Frei Montalva y sus logros en los primeros ocho meses de gobierno, como la nacionalización del cobre, del servicio eléctrico y las telecomunicaciones ${ }^{28}$. El político soviético se mostró favorable a las reformas en Chile, y les hizo saber a los diplomáticos chilenos su intención de entregar asesoría técnica para mejorar la elaboración del cobre, envío de equipos para la obtención de energía eléctrica y la industria minera, entrega de instalaciones industriales, y elementos y técnicos para investigaciones geológicas A través de los acontecimientos que se estaban desarrollando, el cuerpo diplomático chileno en Moscú pudo conseguir las ayudas necesarias en el ámbito técnico para la minería, teniendo además, proyecciones de realizar acuerdos en materia económica-comercial.

\footnotetext{
25 Embajador de Chile en la URSS entre 1965-1968 y Ministro de Educación entre 1968-1970. Pacheco, Máximo y Holger, James. 2009. Recuerdos de la Unión Soviética, p. 7.

${ }^{26}$ AGHMINREL, Fondo Países, Rusia, Vol. 198/ rus/1. Embajada de Chile en Moscú. 1 de diciembre, 1965.

${ }^{27}$ AGHMINREL, Fondo Países, Rusia, Vol. 198/ rus/1. Embajada de Chile en Moscú. 8 de junio, 1965. Confidencial № 10, pp. 2-3.

${ }^{28}$ Alekséi Kosyguin fueel presidente del Consejo de Ministros de la URSS. Junto a Leonid Brézhnev, Primer Secretario y Nikolái Podgorni, presidente del Presidium del Soviet Supremo, ejercieron el denominado "liderazgo colectivo" de la URSS. Remitimos a: Pedemonte, Rafael. 2018. "Desafiando la bipolaridad: la independencia diplomática del gobierno democratacristiano en Chile y su acercamiento con el "mundo socialista" (1964-1970)", Estudos IberoAmericanos, vol 44, $\mathrm{N}^{\circ} 1$, Porto Alegre, pp. 186-199. Pedemonte, Rafael. 2019. "A Case of "New Soviet Internationalism": Relations between the USSR and Chile's Christian Democratic Government, 1964-1970", Journal of Cold War Studies, 21:3, Massachusets, pp. 4-25.
} 
De esta manera, la embajada chilena en Moscú inició una serie de conversaciones en estos ámbitos, siendo una de las primeras la del 9 de agosto de 1965 entre el MINREL y la embajada soviética en Santiago. Posteriormente, el 18 de agosto, en el Ministerio de Comercio Exterior de la URSS comenzó a materializar las conversaciones en vías de llegar a un acuerdo comercial entre ambos Estados ${ }^{29}$. En las negociaciones de estos acuerdos participaron activamente el embajador Máximo Pacheco y James Holger ${ }^{30}$. Luego se sumaron -en febrero de 1966-, Jorge Zabala, gerente asesor de la Corporación de Fomento a la Producción (CORFO), y Carlos Villarroel, gerente de créditos externos del Banco Central.

Tras prolongadas negociaciones tanto en Moscú como en Santiago, el proceso culminó con la firma de tres acuerdos entre ambos países. En primer lugar, un convenio comercial, otro de suministro de maquinaria y equipo $y$, por último, un acuerdo de asistencia técnica y financiamiento de proyectos específicos para la construcción de plantas industriales y otros objetivos. Para James Holger después de la firma de estos convenios, Chile pasó a ser-luego de Cuba y Brasil-, el tercer país latinoamericano en suscribir acuerdos económico-comerciales con la URSS ${ }^{31}$.

El conseguir tan ansiados convenios y sobre todo las relaciones diplomáticas, comerciales y culturales con el bloque soviético, significó no solo un logro en materia de política exterior, sino también afianzar un equipo de trabajo en pos de los objetivos establecidos. En lo cultural dicho sea de paso-, durante estos años visitaron Moscú destacadas figuras chilenas como el pianista Claudio Arrau y el poeta Pablo Neruda ${ }^{32}$.

En este sentido, el embajador Pacheco reconoció el trabajo realizado por Holger, el cual quedó graficado en un documento que emitió a la Cancillería el 1 de diciembre de 1965. Este documento titulado, Precalificación Secretario Holger, dio cuenta, por un lado, de las capacidades profesionales de este como, por ejemplo, su alta formación en política internacional, su perfecto manejo del inglés, francés y amplio dominio del idioma ruso, fundamental para lo que habían sido las negociaciones. Pero también reconoció la importancia para la embajada de los informes que él escribía y que luego enviaban a la Cancillería sobre la política de la URSS, sus conflictos en materia de política exterior y cómo estos repercutían en la política mundial como en los casos de Guinea, Yugoslavia, República Árabe Unida, India y

\footnotetext{
${ }^{29}$ AGHMINREL, Fondo Países, Rusia, Vol. 198/ rus/1. Embajada de Chile en Moscú. 18 de agosto, 1965. Confidencial № 35, p. 1.

${ }^{30}$ AGHMINREL, Fondo Países, Rusia, Vol. 198/ rus/1. Embajada de Chile en Moscú. 18 de agosto, 1965. Confidencial № 35, p. 1.

${ }^{31}$ Pacheco, Máximo y Holger, James. 2009. Recuerdos de la Unión Soviética, pp. 43-55. "Entrevista al académico de número, Máximo Pacheco Gómez", Societas, Academia Chilena de Ciencias Sociales, Políticas y Morales, 2012, N 14, p. 90.

32 Ibídem, p. 91-92. Pedemonte, Rafael. 2018. Desafiando la bipolaridad, p. 192.
} 
Marruecos, como así también los informes sobre la política de la URSS con América Latina y el conflicto Pekín-Moscú.

El documento elaborado por el embajador Pacheco, además, reconoció en Holger sus inquietudes intelectuales, sensibilidad artística, su alta vocación internacionalista y sobre todo la honradez y lealtad, características que para él debiera tener todo buen diplomático al servicio de su país ${ }^{33}$. Dichas características, por lo tanto, nos hablan de un hombre disciplinado no solo en su trabajo político-diplomático, sino también en una forma de conducta de vida, una en que sus emociones como indica Robin Markwica ${ }^{34}$, no sólo moldean el pensamiento sino también el comportamiento, lo cual claramente le impregnó a Holger un lineamiento distintivo de confianza ante el cuerpo diplomático chileno, frente a un escenario complejo como fue el de Guerra Fría y, por cierto, la propia situación internacional que experimentaba la URSS.

Un dato interesante es que estando James Holger en la Embajada de Chile en Moscú, visitó la URSS, junto a otras autoridades chilenas, el entonces senador y luego presidente de Chile, Patricio Aylwin, así que es muy probable que ambos se conocieran antes de gatillarse el "caso Honecker" (1991-1992).

\section{Dividido por el Muro. Las Misiones diplomáticas en la RFA y RDA}

Concluida esta primera misión en la URSS, Holger fue destinado a la República Federal de Alemania (RFA), estuvo en Bonn entre 1968 y 1970, para luego trasladarse a la República Democrática Alemana (RDA), permaneciendo en Berlín entre 1971 y $1972^{35}$.

Su destinación en la RFA como Encargado de Negocios, supuso una vez más, sumergirse en escenarios políticos difíciles y en conflictos diplomáticos latentes en el marco de un sistema internacional bipolar. Recordemos que la RFA no reconocía a la RDA como un país soberano, ni tampoco tenía relaciones diplomáticas con países que reconocieran a éste como Estado, posición conocida como la Doctrina Hallstein ${ }^{36}$. Por su parte, el discurso de la RDA estuvo marcado por la hostilidad de sus dirigentes políticos, respaldado además por los rusos contra

\footnotetext{
${ }^{33}$ AGHMINREL, Fondo Países, Rusia, Vol. 198/ rus/1. Embajada de Chile en Moscú, Precalificación secretario Holger, 1 diciembre, 1965, pp. 1-3.

${ }^{34}$ Markwica, Robin. 2018. Emocional Choices. How the logic of affect shapes coercive diplomacy, Oxford, Oxford University Press.

35 El Mercurio, "Holger, nuevo embajador en Moscú", lunes 9 de septiembre de 1992, p. C 6.

${ }^{36}$ La Doctrina Hallstein fue la base de la política exterior de la Alemania Federal, desde 1955 hasta 1969. Según esta sólo la RFA tenía el derecho exclusivo de representar la herencia de la Alemania histórica (Alleinvertretungsanspruch), así que no reconocía a la RDA como un Estado soberano por lo que bloqueaba todo intento de terceros países que trataran de entablar vínculos diplomáticos con Berlín, amenazando con la ruptura de relaciones y congelamiento de todo acuerdo de cooperación. Véase: Sarotte, Mary Elise Sarotte. 20021 Dealing with the Devil: East Germany, Détente, and Ostpolitik, 1969 - 1973, Chapel Hill, University of North Carolina Press; Gray, William. 2003. Germany's Cold War: The global campaign to isolate East Germany 1949 - 1969, Chapel Hill, The University of North Carolina Press; Werner, Kilian. 2001. Die Hallstein-Doktrin. Der diplomatische Krieg zwischen der BRD und der DDR 1955-1973: Aus den Akten der beiden deutschen Aussenministerien, Berlín, Dunker \& Humblot.
} 
la parte occidental del Muro de Berlín. De esta manera y en la medida que pasaba el tiempo, la tensión entre ambos Estados se mantenía latente.

Ahora bien, cuando llegó Holger a Bonn, las relaciones intraalemanas estaban dando un giro en cuanto a su política exterior y la forma en cómo se relacionaban con sus respectivos aliados $^{37}$. Como explican Asa Briggs y Patricia Clavin ${ }^{38}$, en 1966 en la RFA asumió un gobierno que agrupó a importantes partidos bajo una coalición integrada por la Unión Demócrata Cristiana (CDU), Unión Social Cristiana de Baviera y el Partido Socialdemócrata de Alemania (SPD); en este sentido, si bien no se produjeron cambios drásticos en su política interna de economía social de mercado, sí los hubo en materia de su política exterior gracias a la Ostpolitik impulsada por Willy Brandt, Ministro de Asuntos Exteriores y miembro del SPD. Bajo este mismo ámbito, Peter Calvocoressi, indica que entre 1966 y 1969 la coalición de gobierno de la RFA abandonó la idea de Adenauer de considerar a media Europa como prácticamente inexistente ${ }^{39}$. Asimismo, la distensión entre los países europeos y la creciente preocupación de Europa y Estados Unidos por mejorar sus relaciones con Moscú, comenzaban a generar la idea de que sin la reunificación alemana ningún sistema europeo era factible, por lo tanto, resultaba crucial poner en marcha dos cosas: hacer crecer a las economías de los países de Europa del Este para que dejaran su condición de satélites, y en segundo lugar, la necesidad de comerciar tecnologías con dichas zonas ${ }^{40}$.

Bajo este mismo ámbito, Ricardo Martin de la Guardia y José Díez expresan que la Ostpolitik implementada por el socialdemócrata Willy Brandt tuvo una estrategia diplomática global, la cual estaba destinada a mejorar las relaciones con la RDA y los países de Europa Oriental, siempre y cuando la RFA reconociera los cambios producidos con el fin de la Segunda Guerra Mundial ${ }^{41}$. Es decir, Bonn debía aceptar la formación de un nuevo orden y la existencia de la RDA como Estado soberano. Este ambiente de tensas relaciones en materia de política exterior entre ambas Alemanias, más el bloque soviético con la Europa Occidental en sí, estaba a punto de comenzar a cambiar gradualmente con los nuevos acuerdos diplomáticos y comerciales que Bonn iba a llevar a cabo con los países de la Europa Oriental. Al respecto, Carlos Sanz manifiesta

\footnotetext{
37 Bange, Oliver. 2016. "Onto the Slippery Slope: East Germany and East-West Détente under Ulbricht and Honecker, 1965-1975", Journal of Cold War Studies, Vol. 18, N 3, Massachusetts, pp. 60-94. Dufner, Georg (et. al.). 2016. Deutschland und Chile, 1850 bis zur Gegenwart: Ein Handbuch, Stuttgart: Heinz.

${ }^{38}$ Briggs, Asa; Clavin, Patricia. 1997. Historia contemporánea de Europa. 1789-1989, Barcelona, Editorial Crítica, p. 394. Judt, Tony. 2006. Postguerra. Una historia de Europa desde 1945, Madrid, Taurus, pp. 719-724.

${ }^{39}$ Calvocoressi, Peter. 1999. Historia política del mundo contemporáneo. De 1945 a nuestros días, Madrid, Ediciones Akal, p. 202.

${ }^{40}$ Europa Oriental o Europa del Este, concepto acuñado después de la Segunda Guerra Mundial a consecuencia del Tratado de Yalta y la conquista soviética de casi la mitad de Europa y se utilizó para denominar al bloque de países socialistas: Albania, Alemania Oriental, Bulgaria, Checoslovaquia, Hungría, Polonia, entre otros.

41 Díez, José; Martín de la Guardia, Ricardo. 1998. Historia contemporánea de Alemania (1945-1995), Madrid, Editorial Síntesis, p. 147.
} 
que las relaciones económicas y diplomáticas que la RFA iba a emprender con dichos países, quedaron graficados en dos importantes tratados en 1970. En primer lugar, el Tratado de Moscú, entre la RFA y la URSS, en donde se reconocía la inviolabilidad de las fronteras y la URSS reconocía como Estado soberano a la RFA; en segundo lugar, el Tratado de Varsovia, firmado entre la RFA y Polonia. En este tratado Alemania Occidental aceptaba la línea Oder-Neisse como frontera entre la RDA, y Polonia reconocía la existencia de dos Estados alemanes, lo que implicó que ambos tuvieran reconocimiento y un lugar en la ONU en 1973. Aún con estos acuerdos, la RFA nunca reconoció a la Alemania Oriental como un Estado soberano, pero sí mejoraron sus relaciones diplomáticas ${ }^{42}$. Con la implementación de la Ostpolitik se dejó de lado la Doctrina Hallstein, en donde la RFA no reconocía a la RDA y tampoco mantenía relaciones diplomáticas con los países que si reconocían a la Alemania Oriental. Esta nueva forma de llevar a cabo la política exterior de la Alemania Federal no hubiese sido posible sin la baja de las tensiones entre los países del bloque soviético y los aliados de la RFA, por lo cual la implementación de esta política exterior ayudó al mantenimiento de la seguridad de Europa y de las superpotencias que participaban en la Guerra Fría.

James Holger llegó a la RFA en medio de todo este proceso de cambios intraalemanes. Pero, como él mismo detalla, el proceso de acercamiento diplomático entre los dos Estados fue sumamente difícil más aún, cuando a medida que se acercaban las elecciones en Berlín las amenazas y advertencias de la RDA contra la RFA subían de tono, además la URSS se manifestó en contra de las intenciones de Bonn de llevar la Asamblea Federal a la ciudad de Berlín:

“[...] que el Ministro del Interior de la RDA enviaba una carta al alcalde de Berlín diciendo que dentro de la Asamblea habían Neonazis, (referencia a los 22 miembros del NPD que integran ese grupo), mientras que la RFA se defendía mediante sus voceros acusando que quienes violaban los acuerdos eran "los del otro lado", quienes militarizaban la ciudad. A pesar de la oposición soviética, en el Kremlin han sido más cuidadosos en sus palabras y expresiones para no provocar un quiebre en las relaciones que estaban llevando con la RFA"43. $^{\prime \prime}$.

Como indicábamos anteriormente, Holger escribió ello en directa alusión al hecho que el gobierno de la RFA se había planteado la idea de trasladar la Asamblea Federal a Berlín Occidental. Una propuesta que fue vista como una amenaza por parte de la RDA y que, además, provocó una escalada de tensiones políticas que incluyó a otras potencias europeas como Gran Bretaña, Francia, la propia URSS, y por cierto, Estados Unidos. De allí entonces que Holger viera

\footnotetext{
42 Alija, Adela; Neila, José; Moreno, Antonio; Sáenz, José y Sanz, Carlos. 2018. Historia de las Relaciones Internacionales, Madrid, Alianza Editorial, pp. 171 y ss.

${ }^{43}$ AGHMINREL, Fondo Países, GER, № 57. Embajada de Chile en Bonn, 13 de febrero, 1969. Convocatoria Asamblea Federal en Berlín. Aumentan tensión frente problema, pp. 1-3.
} 
la posibilidad de acercamiento entre ambos bloques no solo como algo complejo, sino que también, como un conjunto de problemas.

Ante estos hechos Holger, testigo ocular de lo que ocurría en Alemania, se interesó como diplomático por mantenerse al tanto de los acontecimientos. En este contexto, los informes que remitió a la Cancillería chilena constituyen una fuente valiosa e importante para conocer el desarrollo de los acontecimientos como, por ejemplo, la visita del presidente de los Estados Unidos, Richard Nixon, a fines de febrero de 1969 a Bonn y Berlín occidental. Holger no solo detalló dicho encuentro, sino que también lo interpretó como un símbolo de respaldo políticomilitar norteamericano al sector occidental, y un apoyo a la convocatoria de la Asamblea Federal para elegir al sucesor del presidente Heinrich Lübke en marzo de ese mismo año. Asimismo, consideró que dicha visita englobaba ciertos objetivos: en primer lugar, demostrar a los aliados de la OTAN que no entrarían en nuevas negociaciones con la URSS; en segundo lugar, potenciar la diplomacia directa y personal a través de la ratificación del Tratado de no Proliferación de Armas Atómicas, mejorando así las relaciones con el presidente francés De Gaulle y finalmente, impulsar la unidad atlántica en planos militares, políticos y económicos. Todo esto coronado, a vista de Holger, por el hecho de que Nixon fuese Republicano, un partido popular en los círculos oficiales de la RFA por sus reconocidas posturas anticomunistas ${ }^{44}$.

Ahora bien, en cuanto a las relaciones que estaban llevando adelante Moscú con Bonn, Holger fue categórico en sostener que día a día éstas se intensificaban. En oficio confidencial informó a la Cancillería chilena, que el conflicto Chino-Soviético (que se había gatillado en 1961 abriendo paso a un conflicto de carácter ideológico ${ }^{45}$ ) no sólo iba en escalada, sino que también les estaba requiriendo a los rusos mejorar su posición con la Europa Occidental de manera de encontrar los apoyos necesarios. Como Alemania era un punto crítico en sus relaciones internacionales, los países del Pacto de Varsovia disminuyeron el nivel de beligerancia en su retórica al referirse a la $\mathrm{RFA}^{46}$.

Si bien, poco a poco existían mejores relaciones con los miembros del Pacto, por otra parte se mantenían ciertas tensiones con algunos estados, como lo que por ejemplo sucedía con el Reino Unido. Al respecto, Holger, planteó en sus informes a Chile, que la visita que realizó el Primer Ministro inglés Harold Wilson a la RFA, después de las complejas relaciones bilaterales a causa de una crisis monetaria, donde Gran Bretaña presionó a la RFA para la revaluación del marco, generó una distención que permitió que las relaciones entre Londres y Bonn mejoran

\footnotetext{
${ }^{44}$ AGHMINREL, Fondo Países, GER, № 57. Embajada de Chile en Bonn, 12 de febrero, 1969. Confidencial № 37/4, pp. 1-3.

45 Zorgbibe, Charles. 1997. Historia de las relaciones internacionales, p. 322.

46 AGHMINREL, Fondo Países, GER, № 57. Embajada de Chile en Bonn, 9 de abril, 1969. Confidencial № 80/17. Dialogo Moscú-Bonn a la luz confronta miento Pekín-Moscú. pp. 1-4.
} 
considerablemente ${ }^{47}$. Por cierto que el interés de los ingleses estaba también puesto en que los alemanes les apoyaran para ingresar a la Comunidad Económica Europea (CEE) siempre y cuando no fuese a expensas de Francia, ya que para los alemanes occidentales, el haber mejorado sus relaciones con los franceses era un activo diplomático a cuidar ${ }^{48}$.

Las negociaciones comerciales en las que participó la embajada chilena en Bonn se vieron seriamente afectadas por el contexto de política exterior de la RFA. En la ciudad de Frankfurt, en la sede del Kreditanstalt für Wiederaufbau (KFW) se realizó una reunión para tratar la solicitud de préstamo para la empresa chilena IANSA por 35 millones de DM, monto destinado a financiar la construcción de una planta remolachera en la ciudad de Curicó, distante 190 kilómetros aproximadamente al sur de Santiago. Era la segunda solicitud de ayuda financiera, anteriormente CORFO había solicitado 20 millones de DM para la planta de celulosa de la ciudad de Constitución ${ }^{49}$. En la reunión participaron miembros de IANSA, los diplomáticos chilenos Enrique Melkonian y James Holger, y miembros de la $\mathrm{KFW}^{50}$. Tras dos meses de negociaciones, la RFA decidió rechazar la solicitud de préstamo, las razones -según Holger- se centraron en tres aspectos: en primer lugar, el elevado monto solicitado por la empresa chilena en momentos que en la disponibilidad de recursos era más bien restringida; además, existió una presión de la propia industria alemana por obtener ayuda financiera; y, por último, Alemania Federal temía que la nacionalización de la gran minería del cobre en Chuquicamata y El Salvador comprometiera la capacidad de pago del gobierno chileno ${ }^{51}$. En este sentido, para Holger la actitud de la RFA se enmarcaba en la restricción y disminución de créditos de la ayuda económica dirigida a América Latina y su redirección a Medio Oriente y Asia en un intento para impedir el reconocimiento internacional de la RDA en esa zona ${ }^{52}$.

Para fines de 1970, James Holger concluyó su misión en Bonn para iniciar un nuevo desafío en su carrera uno que, avant la lettre, no solo marcaría su propia trayectoria diplomática, sino que también la de Chile, al formar parte del equipo que abrió por primera vez una embajada chilena en la RDA. Como describen Medina y Gajardo, Chile logró el acuerdo de establecer relaciones diplomáticas con la RDA en pleno contexto de Guerra Fría. Luego de la Segunda

\footnotetext{
47 AGHMINREL, Fondo Países, GER, № 57. Embajada de Chile en Bonn, 6 de marzo, 1969. Confidencial № 54/10, Visita del Primer Ministro Wilson, pp. 1-5.

48 Íbidem. Martín de la Guardia, Ricardo y Pérez Sánchez, Guillermo. 2001. Historia de la integración europea, Ariel Estudios Europeos, Barcelona, pp. 129 y ss.

${ }^{49}$ AGHMINREL, Fondo Países, GER, № 57. Embajada de Chile en Bonn, 28 de mayo, 1969. Confidencial № 124/23, p. 2.

50 Íbid., p. 1.

${ }^{51}$ AGHMINREL, Fondo Países, GER, № 57. Embajada de Chile en Bonn, 15 de agosto, 1969. Confidencial № 183/38, pp. 1-4.

52 AGHMInREL, Fondo Países, GER, № 57. Embajada de Chile en Bonn, 10 de julio, 1969. Confidencial № 154/30, p. 2. Childs, David. 1969. "East Germany: Towards the twentieth anniversary", The World Today, Vol. 25, № 10, Londres, p. 445. Childs, David. 1997. "East German foreign policy: The search for recognition and stability", International Journal, Vol. 32, N², Londres, pp. $334-551$.
} 
Guerra Mundial Chile se ubicó en la vereda de la democracia liberal y de la economía capitalista, pero con el triunfo de Salvador Allende en 1970 hubo una traslación en el eje de gravedad que hizo a la nación sudamericana acercarse a la órbita soviética ${ }^{53}$. El gobierno chileno designó a Carlos Contreras Labarca ${ }^{54}$ como embajador en la RDA, quién llegó el 31 de mayo de 1971 a Berlín Oriental, el Encargado de Negocios de la embajada sería, James Holger Blair..$^{55}$

El agente de la diplomacia chilena nuevamente se desempeñó en un país crucial para la nueva política exterior de Chile y, curiosamente, para lo que sería el futuro de su vida diplomática. Casi como una ironía del destino el mismo año del establecimiento de relaciones internacionales entre Santiago y Berlín, Erich Honecker asumía como Secretario General del Partido Socialista Unificado de la RDA. Décadas más tarde la vida internacional volvería a cruzar sus destinos en unas condiciones únicas, complejas y sorpresivas, cuando en diciembre de 1991 se desate el denominado "caso Honecker".

La misión de James Holger en Berlín Oriental duró un año, tras ello fue designado por el gobierno de Salvador Allende en 1972 para dirigirse a los Estados Unidos e integrar la Misión Permanente de Chile en Naciones Unidas.

\section{Miembro de la comunidad internacional, su trayectoria en Naciones Unidas.}

El escenario internacional tras la Segunda Guerra Mundial significó, entre otras cosas, buscar una vía legítima que permitiera dar paso poco a poco a una organización universal que tuviera como finalidad promover la paz y la seguridad internacional. En este sentido la creación de la Organización de Naciones Unidas (ONU) permitió a Chile desarrollar un proceso de aprendizaje permanente sobre las relaciones internacionales y le otorgó una tribuna inmejorable para solicitar a la comunidad internacional ayuda destinada a mejorar las condiciones de vida de Latinoamérica ${ }^{56}$.

Bajo este contexto entonces cobra relevancia el que James Holger Blair se haya desempeñado como diplomático durante un largo período en Naciones Unidas, tanto en su calidad de miembro de la misión permanente chilena ante este organismo y, luego, como funcionario de esta organización. Su primera destinación en la ONU fue para apoyar, como Encargado de Negocios, al representante de Chile ante este organismo durante el gobierno de

\footnotetext{
${ }^{53}$ Gajardo, Gustavo y Medina, Cristian. 2019. De la amistad a la Diplomacia. p. 45. Magasich, Jorge. 2013. "La política internacional chilena del gobierno de la Unidad Popular 1970 - 1973: Un intento de pluralismo en las Relaciones Internacionales", Tiempo Histórico, № 7, Santiago, pp. 15 - 27. Fermandois, Joaquín. 1985. Chile y el Mundo. 19701973. La política exterior del Gobierno de la Unidad Popular y el Sistema Internacional, Santiago, Ed. Universidad Católica de Chile.

${ }^{54}$ Carlos Contreras Labarca (1899-1982) fue un abogado y militante del Partido Comunista de Chile, ejerció cargos de Ministro de Obras Públicas (1946-1947), Diputado, Senador y Embajador.

55 Gajardo, Gustavo; Medina, Cristián. 2019. De la amistad a la Diplomacia. p. 59.

56 Ulloa, Erna; Medina, Cristián. 2019. Outline of a diplomatic leader in the international community. p. 963.
} 
Salvador Allende (1970-1973), el poeta Humberto Díaz-Casanueva ${ }^{57}$. Junto a él le tocó recibir a Pablo Neruda durante la visita que realizó el vate a la ciudad de Nueva York en $1972^{58}$.

La llegada de Holger a la ONU, por otro lado, se produjo cuando un nuevo momento de desarrollo y de independencia política de desplegaba en diversas zonas, como era lo que estaba sucediendo en Asia-Pacífico ${ }^{59}$. Juan Carlos Pereira indica que frente a esta situación a inicios de la década del setenta el papel de la ONU fue relevante ya que mediante las Resoluciones 1.514 y 2.625 se vino a definir la autodeterminación como sinónimo de independencia y de libertad ${ }^{60}$. Ante estos conceptos los países se motivaron y dieron legitimidad a sus procesos independentistas al amparo de la ONU.

Una de las zonas más convulsas fueron los territorios de la Franja de Gaza y Cisjordania, donde palestinos e israelitas protagonizaron uno de los conflictos más delicados del siglo XX. Para el historiador Ilan Pappe, los palestinos que vivían en Israel experimentaron importantes cambios, ya que el principal objetivo del movimiento en esos territorios era poner fin a la ocupación israelí ${ }^{61}$. Por su parte, Francisco Veiga sostiene que después de la derrota militar de los árabes en la Guerra de los Seis Días, los grupos políticos palestinos en el exilio integrados en la Organización para la Liberación de Palestina (OLP) optaron por emplear el terrorismo como método para conseguir sus fines ${ }^{62}$.

Todo este clima internacional no le fue ajeno a Chile. James Holger informó al gobierno chileno que el Secretario General de Naciones Unidas, le había enviado el 13 de diciembre (1972) una nota indicándole la designación de oficiales de las fuerzas armadas chilenas como observadores militares en el Organismo de Naciones Unidas para la Vigilancia de la Tregua en Palestina (ONUVT). Y no solo eso, sino que también le solicitó resguardar los procedimientos y funciones del ONUVT, puesto que cada uno de los observadores debía firmar un compromiso de confidencialidad, para así evitar cualquier declaración pública que pudiera afectar la misión en la zona ${ }^{63}$.

La preocupación por el escenario internacional de la década del setenta se tradujo también en la necesidad de buscar una vía para resguardar lo que estaba significando el aumento de

\footnotetext{
${ }^{57}$ El Mercurio, "Holger, nuevo embajador en Moscú", lunes 9 de septiembre de 1992, p. C 6.

58 Quezada, Abraham. 2009. "Neruda - Nueva York - Naciones Unidas", Revista Diplomacia, Academia Diplomática de Chile, $N^{\circ} 119$, Santiago, pp. 89-92.

${ }^{59}$ Remitimos a: lacobelli, Pedro; Robert Cribb, Juan Luis Perello Editores. 2018. Asia y el Pacífico durante los años de la Guerra Fría., Santiago, Fondo de Cultura Económica.

60 Pereira, Juan Carlos (Coordinador). 2001. Historia de las relaciones internacionales contemporáneas., Barcelona, Editorial Ariel, p. 415.

61 Pappe, Ilan. 2007. Historia de la Palestina moderna. Un territorio, dos pueblos, Madrid, Ediciones Akal, pp. 311312.

62 Duarte, Ángel; Ucelay, Enrique y Veiga Francisco. 2006. La paz simulada. Una Historia de la Guerra Fría. Madrid, Alianza Editorial, p. 277.

63 AGHMINREL, Fondo Organismos Internacionales, N.U, № 573. Delegación de Chile ante la Organización de las Naciones Unidas (NU), 27 de diciembre, 1972. OIN № 2246/641.
} 
armas a nivel mundial. Chile fue invitado a participar junto a otros 35 países, por parte de la Asamblea General, en la creación de un Comité especial para la Conferencia Mundial de Desarme, con lo cual el país volvía a sumarse a las iniciativas lideradas por ONU. Holger informó esta iniciativa al ministro de Relaciones Exteriores de Chile, Clodomiro Almeyda, que fue recogida en la Resolución 2.930 de este organismo ${ }^{64}$. Ambas figuras de la diplomacia chilena volverían a encontrarse y tendrían papeles de importancia en el retorno de Chile a la sociedad internacional bajo el gobierno de Patricio Aylwin (1990-1994), a propósito del affaire Honecker.

La participación de Holger en el mencionado Comité fue quizás una de sus últimas gestiones como Encargado de Negocios en la Misión Permanente de Chile ante la ONU, ya que tras el golpe de Estado en Chile (1973), decidió retirarse del servicio exterior ${ }^{65}$. Era evidente que la nueva etapa que se abrió en Chile no respondía a su visión de mundo ni tampoco se alineaba con el trabajo diplomático que había desarrollado bajo los diversos gobiernos democráticos. Ahora bien, las fuentes consultadas, no nos dan cuenta de ninguna opinión o declaración de Holger respecto a la situación de Chile. Si estas existieron fueron en el ámbito más íntimo o doméstico; con todo, es posible intuir que él no compartía las políticas implementadas ni las ideas sustentadas por el régimen de Pinochet. En este punto seguimos a Shirley Götz en cuanto a la necesidad de observar retrospectivamente la personalidad de un líder o personaje diplomático para aquilatar su accionar ${ }^{66}$.

Ahora bien, esta decisión de alejarse del ámbito diplomático no significó que su espíritu de servicio público exterior menguara su carrera como diplomático, por el contrario, el escenario internacional lo motivó a seguir desarrollando sus lineamientos en esta materia, pero ahora bajo el alero directo de la ONU. Desde febrero de 1977 hasta marzo de 1990 trabajó como funcionario del organismo internacional en diversas tareas. En primer lugar, ocupó el cargo de asistente ejecutivo del Rector de la Universidad de Naciones Unidas en Tokio entre los años 1977-1978, para luego desempeñarse como asesor político de la fuerza de paz de la ONU en el Líbano entre los años 1979 a 1981. Posteriormente, asumió como Encargado de Asuntos del Medio Oriente dependiente de la Subsecretaria de Asuntos Políticos Especiales de la Secretaria General en Nueva York, durante un año, para luego asumir, ante esta misma entidad, como Representante Especial Alterno para el bienio 1982-1984.

Tras este periodo, fue nombrado Representante Especial del Secretario General, en Chipre (UNFICYP) entre los años 1984-1988, en donde además debió hacerse cargo de las

\footnotetext{
${ }^{64}$ AGHMINREL, Fondo Organismos Internacionales, N.U, № 573. Delegación de Chile ante la Organización de las Naciones Unidas (NU), 27 de diciembre, 1972. OIN № 2248/643.

${ }^{65}$ Entrevista a Jaime Carrasco realizada el 1 de octubre de 2019 en la ciudad de Chillan. Junta de Gobierno, República de Chile, Acta N 150-A, 29 de agosto de 1974.

${ }^{66}$ Götz, Shirley. 2015. Liderazgo y política exterior, Santiago, Ril editores.
} 
negociaciones entre las comunidades griegas y $\operatorname{turcas}^{67}$. Finalizada su misión allí, volvió a Washington para asumir la dirección del Centro de Información de la ONU durante los años 1988 y 1990, no sin antes, puntualmente en marzo de 1988, responder nuevamente a la confianza del Secretario General, quien le solicitó que investigara las acusaciones sobre el uso de armas químicas en Irán e Irak $^{68}$.

Tras este amplio periodo de funciones y trabajo como funcionario de Naciones Unidas, comenzó para James Holger un nuevo camino marcado por el retorno de Chile a la democracia. La reinserción del país en el escenario internacional junto a la participación activa de Chile en Naciones Unidas, tras los años de la dictadura de Augusto Pinochet, implicaron desplegar las mejores estrategias posibles. En este marco, Aylwin sabía que necesitaba funcionarios públicos comprometidos con lo que era no solo su programa de Gobierno, sino que también delegados que tuvieran un vasto conocimiento de una sociedad internacional en pleno proceso de transformación. Es ahí cuando el presidente Aylwin llamó a Holger para que se reincorporara al servicio exterior chileno como representante permanente alterno de Chile ante la ONU, misión que comenzó a cumplir desde abril de $1990^{69}$.

Al respecto, fuentes oficiales de Naciones Unidas indicaron que Holger lideró como representante de Chile diversas iniciativas. Una primera participación estuvo marcada por la preocupación del gobierno chileno ante el Plan de Conferencias y el presupuesto destinado a ello, lo que fue tratado en la 11a sesión de la Asamblea General en su quinta comisión celebrada en octubre de $1990^{70}$. En este sentido, existía por parte de las diversas delegaciones, inquietud entorno a la utilización óptima de nuevas tecnologías que permitieran asegurar un buen servicio de conferencias, en términos de mejorar la precisión de los servicios de interpretación, sobre todo para los grupos regionales en Ginebra, Nueva York, Viena y en todos los centros de conferencias de Naciones Unidas. Situación compleja, ya que el Departamento de Servicios de Conferencias (DSC), que incluía el propio servicio de traducción, tropezaba con la dificultad de dar cumplimiento a la norma de seis semanas para la publicación de los documentos generados en cada encuentro, situación no menor, ya que la tardanza de estos producía que se retrasara o derechamente no alcanzaran a llegar dicha información a todas las delegaciones obstaculizando el análisis de estos.

67 El País (España), 19 de abril de 1986. http://www.operationspaix.net/306-biographie-de-holger-james.html consultado el 10 de julio de 2020. Guevara, Leticia; Feliú, Fernando. 2011. Participación de Chile en operaciones de paz de Naciones Unidas: Misión Haití y análisis del nuevo marco jurídico nacional, memoria para optar al grado de Licenciado en Ciencias Jurídicas y Sociales, Facultad de Derecho, Departamento de Derecho Internacional, Universidad de Chile, p. 65 y ss.

68 El Mercurio, "Holger, nuevo embajador en Moscú", lunes 9 de septiembre de 1992, p. C 6.

69 Ministerio de Relaciones Exteriores, Misión Permanente ante las Naciones Unidas. Archivo Digital Patricio Aylwin [En adelante ADPA], "Embajador alterno ante UN, 26 de noviembre de 1992", CL CLUAH 1-109-5-1,

70 Naciones Unidas, A/C.5/45/SR.11, Summary record of the 11th meeting: 5th Committee, held on Wednesday, New York, General Assembly, 45th session, 17 October 1990. 
Por otro lado, también estaba la inquietud de no respetar el límite de 32 páginas para los informes de los órganos subsidiarios a la Asamblea General, previo a los periodos de sesiones, lo que provocaba dos problemas. En primer lugar, y ligado a lo anterior, que los representantes de las diversas delegaciones no contaban con el tiempo suficiente para la correcta lectura de fondo de estos informes, y segundo, que estos debían ser lo suficientemente legibles para aquellos representantes que no eran miembros de los órganos subsidiarios de la Asamblea General.

La postura de Chile al respecto se encuentra en un breve pero sentencioso discurso que pronunció Holger, donde si bien reconoció los esfuerzos por alcanzar mejoras en estos planos, de todas maneras, resultaba necesario que se estudiara las recomendaciones propuestas, sobre todo en el ámbito de las metodologías a desarrollar. Más categórico fue sobre la norma de las seis semanas: "La situación se ha hecho más crítica en el actual periodo de sesiones de la Asamblea General, al hacer que dos de las Comisiones Principales, la segunda y la tercera, se vieran obligadas a modificar sus programas de trabajo por no haber recibido a tiempo los documentos necesarios" ${ }^{71}$, una alusión, por cierto, no solo dirigida al obstáculo que significaba esto para los propios órganos de Naciones Unidas, sino también a aquellas delegaciones más pequeñas, como era el caso de Chile. De esta manera, Holger llamó a dar muestras de moderación y de continuar con los esfuerzos para lograr los objetivos trazados.

Iniciando la década de los noventa se presentó el tema del desarme. En lo referido a la participación de Chile y de James Holger en las sesiones de la Asamblea General, el eje se colocó en la apertura del trabajo de la Conferencia de Desarme, la cual resultaba ser el único foro de negociación multilateral en dicha materia. La preocupación de Chile, en su calidad de observador, era la real efectividad de esta Conferencia ya que sentía una falta de voluntad política de algunos de sus miembros, a lo que sumó un sistema internacional en plena transformación con la desaparición de los bloques ideológicos y la reunificación de Estados, lo que era un llamado para contribuir a la política de desarme y, por otro, cuidar la manera en cómo resolver los desafíos que aún se mantenían latentes en ese aspecto.

Holger va a plantear en la 18a sesión de la Primera Comisión del cuadragésimo quinto periodo de sesiones de la Asamblea General, celebrada el 26 de octubre de 1990, esta preocupación en materia de seguridad internacional, puntualmente frente a la prohibición absoluta de ensayos nucleares. En este sentido, el embajador llamó directamente a las delegaciones a estar alertas porque solo un grupo reducido de naciones velara por la proscripción de ensayos nucleares cuando sus efectos y consecuencias afectaban a todos por igual. Esto era una alusión directa al Tratado de Moscú de 1963, ya que cuando se firmó, 5 de agosto, solo estuvieron presentes, además de Nikita Kruschev, los ministros de asuntos

71 Ídem. 
exteriores de Estados Unidos, la Unión Soviética, Reino Unido, y el Secretario General de la ONU, el birmano U-Thant. Además de aquello, también preocupaba a Holger la idea del restablecimiento de un comité ad hoc dentro de la misma Conferencia de Desarme. Él cuestionaba su real eficacia para contar con los elementos necesarios que lo llevara a eliminar dichos ensayos nucleares. Sus palabras fueron:

"Es un hecho cierto que las explosiones nucleares tienen consecuencias adversas para el medio ambiente. Así ha sido reconocido en este mismo foro por países que no tienen un interés directo comprometido en el tema, además de innumerables organismos científicos con autoridad en la materia. Chile y los demás miembros de la Comisión Permanente del Pacífico Sur, han denunciado en innumerables ocasiones los ensayos nucleares efectuados en el área geográfica de competencia de la Comisión y no claudicarán en sus esfuerzos para obtener el término absoluto de tales pruebas" ${ }^{\prime 2}$.

Para Chile era importante un proceso de negociación sobre desarme y era crítico de la labor que se estaba llevando a cabo por dos aspectos. En primer lugar, porque sentía que se estaba demorando mucho las negociaciones para poner fin a las armas químicas y, en segundo lugar, sentía que se estaban generando elementos discriminatorios que favorecían la posición de algunos países en perjuicio de otros, y que no se establecían normas que impidieran la destrucción total y simultánea de todos los arsenales químicos.

Ligado al tema de desarme, Chile abogó para que se asignaran los recursos económicos necesarios para hacer frente a las consecuencias devastadoras de la utilización de este tipo de armas, como era el efecto sobre el medio ambiente ${ }^{73}$. Bajo este mismo contexto, una temática que Holger analizó en la Universidad de las Naciones Unidas (creada en 1972), era el hecho de la urgente colaboración con este órgano educacional para potenciar la investigación tanto en ciencia como en tecnología, siendo resorte de cada país miembros de ONU colaborar en este aspecto $^{74}$.

Ya para el año 1991, una de las últimas intervenciones como delegado ante ONU, estuvo vinculada a las Operaciones de Paz, en un momento de hostilidades en el Golfo Pérsico, conflicto en la ex Yugoslavia, y el trabajo como observador en las elecciones de Namibia y Nicaragua. Bajo este escenario, entonces, y ante la diversidad de tareas a cumplir, la mirada de Holger se centró en la necesidad de definir bajo esta amplitud temática, el concepto de mantenimiento de la paz:

\footnotetext{
72 Naciones Unidas, A/C.1/45/PV.18, Verbatim record of the 18th meeting: 1st Committee, held on Friday, New York, General Assembly, 45th session, 26 October 1990, p.6.

73 Íbid., p.8.

74 Naciones Unidas, A/C.2/45/SR.48, Summary record of the 48th meeting: 2nd Committee, held on Monday, New York, General Assembly, 45th session, 26 November 1990, p.4.
} 
"Las nuevas funciones que el personal de mantenimiento de la paz está llamado a realizar, hacen necesario estudiar el posible empleo de civiles para desempeñar funciones que actualmente lleva a cabo personal militar. Por otra parte, el costo de las operaciones en las que participan civiles es mucho más elevado que el de las operaciones más tradicionales"75.

Junto a lo anterior, para Holger era necesario debatir sobre el concepto de diplomacia representativa, a la luz de los diversos conflictos vigentes y la responsabilidad que en ello recaía a Naciones Unidas. Según él, este concepto tenía por rol fundamental tres importantes aspectos: prevenir guerras, contener los conflictos y propiciar el diálogo entre los Estados. Por lo tanto, para Holger, la misión central de esta diplomacia representativa debía contribuir al establecimiento de un sistema de seguridad colectivo viable en que también la coordinación de la asistencia y ayuda humanitaria resultase ser un asunto no solo decisivo, sino que también crucial al amparo de organismo multilateral ${ }^{76}$.

\section{El reencuentro: El "Caso Honecker" y James Holger}

Para fines de 1991 un ya experimentado James Holger tuvo que emprender complejas negociaciones tripartitas, junto con ser testigo y protagonista privilegiado de un auténtico puzzle en política internacional que tuvo que afrontar el gobierno de Patricio Aylwin a poco tiempo de instalarse en La Moneda.

La recién estrenada transición chilena a la democracia se vio inesperadamente envuelta durante la temprana Guerra Fría en una de las crisis diplomáticas más importantes, tensionando las relaciones con la Alemania de Helmut Kohl y la Rusia de Boris Yeltsin. Erich Honecker, reconocido líder de la extinta RDA y una figura clave del bloque soviético, llegó el 11 de diciembre de 1991, en compañía de su esposa Margot, a la embajada chilena en Moscú donde permanecieron como "huéspedes" durante varios meses"

Tras la disolución de la URSS ${ }^{78}$, y estando Boris Yeltsin en el poder, Honecker, gracias a una invitación de sus viejos camaradas comunistas, vivía en una dacha cerca de Moscú cuando fue

\footnotetext{
75 Naciones Unidas, A/C.1/45/PV.18, Summary record of the 15th meeting: Special Political Committee, held on Friday, New York, General Assembly, 46th session, 1 November 1991, p. 6.

${ }^{76}$ Naciones Unidas, A/46/PV.42, Provisional verbatim record of the 42nd meeting, held at Headquarters, New York, on Tuesday, 5 November 1991, pp. 40-42.

77 Medina, Cristian (et.al.). 2018. "El huésped (in)esperado. Erich Honecker en la embajada de Chile en Moscú", En: Lilón, Domingo y Deák, Máté, Encuentros. Europa-Iberoamérica en un mundo globalizado, Pécs, Centro iberoamericano Universidad de Pécs, Hungría, pp. 49-60.

78 Poch de Feliú, Rafael. 2003. La gran transición. Rusia, 1985-2002, Barcelona, Crítica; Brzezinski, Zbigniew. 1989. El gran fracaso: Nacimiento y muerte del comunismo en el siglo veinte, Buenos Aires, Javier Vergara Ed.; Bukovski, Vladimir. 1991. La Unión Soviética: de la utopía al desastre, Madrid, Arias Montano Editores; Daniels, Robert. 1993. The end of the communist revolution, London: Routledge; Jovitt, Ken. 1992. New World Disorder. The leninist
} 
notificado el 10 de diciembre de ese mismo año, que sería expulsado del territorio ruso en un plazo de tres días ${ }^{79}$. Sobre Honecker pesaba una orden de detención desde Alemania y debía comparecer ante sus tribunales para ser juzgado. La medida puso en serios aprietos al matrimonio germano oriental. Frente a esto y ya sin muchas opciones, el día 11 de diciembre de 1991 el matrimonio Honecker decide asistir a la embajada chilena en Moscú invitados por Irma Cáceres, esposa de Clodomiro Almeyda, entonces el embajador chileno en Rusia ${ }^{80}$. Mientras el matrimonio germano oriental estaba en la legación diplomática, Erich Honecker abruptamente se sintió mal de salud, por lo que se optó que se quedara allí. Desde ese momento se desató un issue diplomático que obligó a desplegar las mejores herramientas diplomáticas de Chile en la búsqueda de una solución ajustada a su tradición en política exterior.

Al respecto, surgieron distintas versiones del cómo y por qué los Honecker recibieron por parte de Gobierno chileno la categoría de "huéspedes". En este sentido, el Encargado de Negocios de la Embajada, José Miguel Cruz, indicó que el Gobierno no estaba al tanto de lo que iba a suceder, sino que fue la esposa de Almeyda la que había decidido por mutuo propio dejarlos hospedados ${ }^{81}$. En lo concreto y de acuerdo a la documentación oficial, La Moneda confirmó que Honecker podía permanecer en la Embajada chilena como huésped mientras se buscaba una solución al asunto ${ }^{82}$. Ahora bien, una cosa que debe quedar en claro en torno a la llegada y permanencia de Honecker en la embajada y tal y como declaró el propio ex mandatario este-alemán, el gobierno chileno no le dio asilo político ni él lo solicitó, solo expresó su deseo a las autoridades de poder viajar a Chile para estar junto a su hija y nietos, que vivían en Santiago desde $1990^{83}$.

extinction, Berkeley, University of California Press; Martín de la Guardia, Ricardo, Pérez, Guillermo. 1995. La Unión Soviética: de la perestroika a la desintegración, Madrid, Itsmo; Martín de la Guardia, Ricardo, Pérez, Guillermo. 1993. El sueño quedó lejos. Crisis y cambios en el mundo actual, Valladolid, Secretariado de Publicaciones, UVA; Martín de la Guardia, Ricardo. 2012. 1989, el año que cambió el mundo. Los orígenes del orden internacional después de la Guerra Fría, Madrid, Akal; Taibo, Carlos. 1991. Unión Soviética. La quiebra de un modelo, Madrid, Los Libros de la Catarata; Kramer, Mark. 2003. "Special Issue: The Collapse of the Soviet Union (Part 2): Introduction", Journal of Cold War Studies, vol. 5, № 4 (2003), pp. 3-42; Carrére D`Encausse, Hélène. 2016. Seis años que cambiaron el mundo. 1985.1991, Ariel, Barcelona.

79 Medina, Cristian, Gajardo, Gustavo. 2017. "De apátrida errante a vecino santiaguino. El "caso Honecker", desde las fuentes oficiales (1991-1994)". Tzintzun. Revista de Estudios Históricos, № 65, Morelia, p. 264.

80 "Ich bin im politischen Asyl" Der Spiegel (DS), Hamburg, N²3, 1991, pp. 37-45. "Kein Herz für Honecker", DS, Hamburg, N²7, 1991, p. 17. "Ein Prozeß ohne Ende?" , DS, Hamburg, N 51, 1991, pp. 18.-21.

81 Medina, Cristian; Gajardo, Gustavo.2019. “Chile y el amigo alemán. El “caso Honecker”. 1991-1994: tensión internacional en la temprana posguerra fría". Cuadernos de Historia, № 50, 2019, Santiago, pp. 136-137.

82 Ibídem, p. 137.

${ }^{83}$ AGHMINREL, Télex Ordinario Urgente № 564, Gobierno de Chile, Embajada en Federación Rusa, Moscú, 12 de diciembre 1991. Medina, Cristian; Gajardo, Gustavo 2016. "Entre protectores y opositores: Labor política frente al caso Honecker”. Revista de Ciencia Política, Vol. 36, № 3, 2016, p. 734. 
La llegada y permanencia de los Honecker en la sede diplomática en Moscú generó problemas entre Chile, Alemania y la Federación Rusa. En este sentido, la situación representó un complejo escenario en el que los rusos no realizaron ninguna declaración inmediata ni contacto directo con autoridades chilenas. Para ellos, esto era competencia de los otros países involucrados, dejando, por lo tanto, el asunto en manos del gobierno de Aylwin y abriendo un panorama complejo con la Alemania de Kohl, quien exigió la extradición "sumaria e inmediata" del exjerarca germano oriental a Bonn ${ }^{84}$.

Esta situación de conflicto diplomático tripartito significó un duro y, en cierto modo, inesperado golpe a la política exterior chilena de la transición democrática y de reinserción internacional posdictadura. La irrupción del "caso Honecker" dificultó esta labor alterando la estrategia que buscaba posicionar a nivel internacional la imagen país de Chile ${ }^{85}$. El que se diera refugió a Erich Honecker, acusado de crímenes de lesa humanidad y violación de los Derechos Humanos, dejaba sentimientos encontrados. Para sectores de la izquierda chilena - socialistas y comunistas- esta era una oportunidad única para "devolver la mano" a quien había recibido a un grupo importante de chilenos exiliados durante la dictadura militar, pero según la derecha política se estaba amparando a un dictador.

Frente a tal escenario, el gobierno chileno comenzó a barajar diversas soluciones a este conflicto. Una de las primeras ideas que surgió, fue el trasladar a Honecker a un tercer país, por lo que la orden emanada desde la Cancillería era ver la factibilidad de ello, incluso Corea del Norte ofreció su ayuda, pero existía un tema no menor ya que Honecker no poseía pasaporte y los rusos se negaron sistemáticamente a otorgarle un permiso para abandonar su territorio indicando que este se encontraba en zona chilena, por lo tanto, no les correspondía a ellos entregar dicha documentación ${ }^{86}$. Por otro lado, la posibilidad de que viajara a Santiago era rechazada por las autoridades chilenas ya que, como cualquier ciudadano extranjero, para ingresar al territorio nacional debía hacerlo con su pasaporte y Honecker no lo tenía. Asimismo, si bien se sabía que existía una orden de detención en su contra, también estaban los problemas de salud Honecker, que llevó a las autoridades chilenas a considerar el factor humanitario como una vía de solución diplomática y política ${ }^{87}$.

Mantener a Honecker en la embajada y no entregárselo a las autoridades alemanas bajo estos argumentos, generó serios cuestionamientos al gobierno de Aylwin por parte de ellos. Así

\footnotetext{
${ }^{84}$ AGHMINREL, Télex Ordinario Urgente № 580, "Declaraciones Canciller de Rusia sobre Caso Honecker", Gobierno de Chile, Embajada en Federación Rusa, 17 de diciembre de 1991. Medina, Cristián, Gajardo, Gustavo. 2017. De apátrida errante a vecino santiaguino, p. 266.

85 Medina, Cristián; Gajardo, Gustavo. 2016. Entre protectores y opositores, pp. 735-736.

${ }^{86}$ Medina, Cristián; Gajardo, Gustavo. 2019. Chile y el amigo alemán, pp. 140-141.

87 ADPA, "Carta del presidente de la República de Chile, Patricio Aylwin, al Canciller de la República Federal de Alemania, Helmut Kohl, 16 de diciembre de 1991", CL CLUAH 1-72-2-6. Medina Cristián; Gajardo, Gustavo. 2019. Chile y el amigo alemán, p. 146.
} 
y en un intento para mejorar la situación, el presidente chileno designó a James Holger Blair y a Roberto Cifuentes como embajadores especiales ante los gobiernos de Rusia y de Alemania con la misión de buscar una solución al problema ${ }^{88}$.

La designación de Holger para esta tarea fue idea del abogado y político Máximo Pacheco Gómez. En una conversación con el presidente Aylwin, este le consultó a quien podría designar para dicha misión: "Le respondí que la persona indicada era Jimmy Holger. Entonces habló con Jimmy y lo nombró embajador. Fue un magnífico embajador" ${ }^{89}$. La estrategia que planteó el gobierno, entonces, fue formar una comisión para que los tres países involucrados en este conflicto lograran un acuerdo a la brevedad y así sacar a Honecker de la embajada ${ }^{90}$.

La misión de Holger no era nada fácil, la crisis había llegado a tal nivel que en el Bundestag hubo conversaciones para ver la posibilidad de suspender las ayudas económicas a Chile hasta que Honecker fuera entregado ${ }^{91}$. Por su parte, en el plano nacional comenzaban a aflorar las críticas de los diversos sectores políticos:

“El gobierno estaba recibiendo acidas críticas por parte de partidos de oposición, tales como Renovación Nacional (RN), y dentro de la misma coalición de gobierno, el Partido Socialista (PS) tenía una cercanía ideológica con Honecker y, además, un número considerable de sus militantes fueron recibidos en la RDA durante el Régimen Militar en Chile, por lo que sus posiciones eran claramente en favor del ex jerarca socialista, por lo tanto, el PS presionaba al gobierno para conceder el asilo político a Honecker y haciéndolo viajar a Chile formalmente, de lo contrario, amenazaron con retirarse de la coalición, lo que traería consecuencias graves, pues el PS era fundamental en la Concertación" ${ }^{92}$.

Bajo este escenario de declaraciones, la tarea de Holger se dificultaba, debiendo seguir estrictamente las instrucciones emanadas desde la Cancillería que se centraron en tres puntos claves: en primer lugar, buscar una solución jurídica, en segundo lugar, convencer a Honecker que no podía permanecer por más tiempo en la embajada, y en tercer lugar, negociar con rusos y alemanes una salida digna del ex mandatario, en donde se le respetaran sus derechos ${ }^{93}$. Al

\footnotetext{
88 Medina, Cristián; Gajardo, Gustavo. 2017. De apátrida errante a vecino santiaguino, pp.267-268.

89 S/A, 2012. Entrevista al académico de número Don Máximo Pacheco Gómez, Societas. Revista de la Academia Chilena de Ciencias Sociales, Políticas y Morales, № 14, Santiago, p. 92.

${ }^{90}$ AGHMINREL, Fondo James Holger, vol. 1, "Télex secreto N 8", 8 de abril de 1992; "Télex secreto N 11 ", 8 de abril de 1992; "Télex secreto N 13", 8 de abril de 1992; “Carta del presidente de la Federación Rusa, Sr. Boris Yeltsin, al presidente Patricio Aylwin", Cámara de Diputados, 22 de abril de 1992, Sesión 25a. Ordinaria, 5 de agosto de 1992, p. 2051. ADPA, "Entrevista al presidente de la República, Patricio Aylwin, en Diario 16 de España, 22 de abril de 1992", CL CLUAH 1-3-1-8.

91 Medina, Cristián; Gajardo, Gustavo. 2019. Chile y el amigo alemán, p. 151.

92 Medina, Cristián; Gajardo, Gustavo. 2016. Entre protectores y opositores, pp. 742-744.

93 AGHMINREL, Fondo James Holger, vol. 1, "Cable secreto N4, marzo, 1992"; "Cable secreto N 6, marzo, 1992".

"Tendencias", Revista Hoy, 23 de marzo de 1992, "Sonderbotschafter Chiles verhandelt im Fall Honecker",
} 
estar Honecker con serios problemas de salud e imposibilitado de poder ir a un hospital, Holger hizo gestiones para que un médico de la embajada británica lo visitara y constatara su real estado $^{94}$. En este sentido, debemos indicar que el gobierno chileno veló por otorgar las condiciones suficientes para que Honecker en su calidad de "huésped" fuese bien atendido, a tal punto, por ejemplo, que asumió todos los gastos médicos, los que ascendieron a un monto de US\$ 4.369. ${ }^{95}$

Paralelo a lo que sucedía en Moscú y de acuerdo a la documentación diplomática, el camino para solucionar esta crisis también comenzó a gestarse en un encuentro entre el canciller Helmut Kohl y el presidente Aylwin en el marco de la Conferencia Mundial sobre Medio Ambiente y Desarrollo en la ciudad Río de Janeiro en junio de 1992, donde Kohl reiteró que su gobierno no cedería ante la exigencia principal, que era que Honecker debía comparecer ante la justicia alemana, por lo tanto, para Aylwin cualquier otro camino ya no era viable ${ }^{96}$.

El Embajador Holger precisó que desde La Moneda se fijó un curso de acción para que Honecker abandonara la Embajada. Al respecto dijo: “(...) yo voy a Moscú con un objetivo muy claro. Y aquí estoy no interpretando sino reflejando la posición del presidente Patricio Aylwin y del Gobierno, de lograr que el señor Honecker haga abandono de la Embajada" ${ }^{97}$.

Finalmente, el trabajo de Holger comenzó a dar luces en julio de 1992 cuando el gobierno ruso comunicó a Alemania que había solicitado oficialmente la extradición de Honecker para su regreso inmediato a territorio alemán ${ }^{98}$, el que se concretó puntualmente el día 29 de ese mes. La salida de Honecker de la embajada dejó, lo que consideramos una de las imágenes más icónicas de este intrincado caso, un Honecker saliendo con su puño derecho cerrado en alto acompañado del propio embajador James Holger, secundado por su esposa Margot, y los diplomáticos chilenos Jorge $\mathrm{O}^{\prime}$ Ryan y José Miguel $\mathrm{Cruz}^{99}$.

Si bien existieron rumores, a nivel de prensa, de una compleja relación entre el otrora jerarca alemán y el embajador chileno, lo concreto es que este último ejerció como un gestor diplomático al servicio de Chile. El año 2009 en una entrevista a la revista Qué Pasa, declaró que su último recuerdo de Honecker saliendo de la embajada chilena en Moscú, fue cuando

Süddeutsche Zeitung, 17 de marzo de 1992; "Chile schickt zweiten Honecker-Gesandten”, Süddeutsche Zeitung, 19 de marzo de 1992. Medina, Cristián; Gajardo, Gustavo. 2019. Chile y el amigo alemán, p.160.

${ }_{94}^{94}$ Medina, Cristian (et.al). 2018. El huésped (in)esperado, p. 6.

95 AGHMINREL, Oficio Reservado № 004, Comprobante de Contabilidad № 229, Gobierno de Chile, Embajada en Federación Rusa, Moscú, 12 de abril 1992. Medina, Cristián; Gajardo, Gustavo. 2016. Entre protectores y opositores, p. 738.

${ }^{96}$ Memoria del Ministerio de Relaciones Exteriores, 1992, p. 77. Medina, Gajardo. Chile y el amigo alemán. 2019. p. 158.

97 El Mercurio, "Holger lleva instrucciones que Honecker deje embajada", 10 de junio de 1992; La Nación, "Holger viaja a lograr que Honecker salga", 10 de junio de 1992.

98 Medina, Cristián; Gajardo, Gustavo. 2017. De apátrida errante a vecino santiaguino, p. 277.

99 Ídem., pp. 277-278. 
este le agradeció por respetarlo en su condición de ex Jefe de Estado y como persona, por lo que estaba profundamente agradecido de él ${ }^{100}$.

Así, con un Honecker rumbo a Alemania culminó para James Holger la que fue quizás su misión diplomática más importante y compleja en la que tuvo que desplegar todas sus capacidades y experiencia internacional para lograr la salida del ex jerarca de la misión chilena en Moscú. Como él mismo los reconoció:

“(...) pocos días antes de la partida del Sr. Honecker esas conversaciones habían llegado a un total impasse (...) logramos superar la situación a través de una fórmula de última hora que, sin comprometer nuestros principios, dio a la parte rusa la necesaria "salvada de cara" para aceptarla. De no haber asumido nosotros esa actitud, el Sr. Honecker estaría todavía en nuestra embajada con el riesgo de que su permanencia se hubiese consolidado, transformándose con ello al huésped en un segundo Cardenal Mindzensky con los efectos que ello hubiese causado" ${ }^{101}$.

\section{Últimos momentos}

Tras los intensos meses como embajador especial para resolver el caso Honecker, el gobierno de Patricio Aylwin consideró que la persona más idónea para asumir la dirección de la embajada chilena en Moscú para el periodo 1992 a 1997 era James Holger Blair ${ }^{102}$. La designación fue vista como retribución y reconocimiento por la ardua tarea de negociación que tuvo que enfrentar el diplomático.

Tras finalizar su periodo en Moscú Holger volvió a la ONU al alero del Consejo de Seguridad vinculado a la Fuerza de las Naciones Unidas para el Mantenimiento de la Paz en Chipre (UNFICYP), llegando a ser el jefe de la misión en $1999^{103}$. Asimismo, se desempeñó como asesor para las Fuerzas de Naciones Unidas en el Líbano (UNFIL) y director del Centro de Informaciones de Naciones Unidas en Washington. En cuanto a su última etapa como diplomático, la realizó en el ámbito nacional, como subdirector de la Academia Diplomática de Chile "Andrés Bello"104.

\footnotetext{
100 Qué Pasa, "Algunos pensaban que Honecker se suicidaría", 7 de noviembre de 2009.

101 AGHMINREL, Fondo James Holger, vol. 1, "Télex secreto S/N", de Embajador James Holger al Ministro de Relaciones Exteriores de Chile, 31de agosto de 1992.

102 Pacheco Máximo; Holger, James. 2009. Recuerdos de la Unión Soviética, p. 10.

103 Noticias Navales, "Parte a Misión de Paz en Chipre nuevo contingente de la Armada", 21 de febrero de 2018. Extraído desde: https://www.radionaval.cl/armada/noticias-navales/parte-a-mision-de-paz-en-chipre-nuevocontingente-de-la-armada/2018-02-21/105304.html. Consultado el 16 de diciembre de 2019.

104 Ministerio de Relaciones Exteriores. (2019). Minrel.gob.cl. Extraído desde: https://minrel.gob.cl/cancillerialamenta-el-fallecimiento-de-embajador-james-holger-blair/minrel/2014-08-04/175919.html. Consultado el 16 de diciembre de 2019.
} 
Finalmente, y tras cerca de sesenta años de servicio exterior, James Holger falleció el 14 de agosto de 2014, dejando como legado una intensa labor diplomática marcada por las relaciones internacionales y su constante trabajo en organismos como Naciones Unidas ${ }^{105}$.

\section{Consideraciones finales}

La historia diplomática de Chile está marcada por gestores que brindaron su impronta personal en el trabajo realizado al servicio de su país. Este es el caso de James Holger, un profesional de la diplomacia chilena. Por lo tanto, conocer su trayectoria individual permite adentrarse en la gestión de un observador y protagonista de momentos cruciales en la dinámica histórica internacional de Chile y del mundo.

La labor de Holger no solo se enmarcó en el ámbito político-diplomático, sino que también su impronta se reflejó en el ámbito cultural que impulsó en cada una de las misiones que cumplió para Chile. En este sentido y motivado por su esposa, Cecilia Becerra, organizó, por ejemplo, en la embajada de Moscú, diversos conciertos de música invitando a artistas chilenos como Alfredo Perl ${ }^{106}$, Luis Muñoz Penrroz ${ }^{107}$, Oscar Quezada ${ }^{108}$, así como al maestro Claudio Arrau, con quién Holger tuvo una profunda amistad. Estas iniciativas acercaron a los chilenos residentes con sus raíces y brindaron la oportunidad a aquellos músicos chilenos de mostrar su arte en otros espacios. Esto nos habla de un diplomático motivado no solo por ser parte de un mundo marcado por una diplomacia activa en lo democrático, sino también de una cosmovisión de mundo integral, en que la cultura bajo sus diversas aristas no solo era parte de su vida, sino que también buscaba que esta fuera parte presente en todo lo que fue su labor como diplomático chileno y agente internacional, ya lo dice Robin Markwica “cada lógica de elección captura elementos importantes de la vida política" ${ }^{109}$.

James Holger tuvo una riquísima vida diplomática que lo llevó inesperadamente a lugares y situaciones internacionales que lo convirtieron en un testigo y actor privilegiado de los cambios y tensiones del sistema internacional. Lideró misiones diplomáticas complejas y difíciles por lo que conocer su gestión internacional permite responder a las interrogantes planteadas al inicio del presente artículo y, sobre todo, dar cuenta que la hipótesis sostenida nos lleva a indicar que efectivamente fue un testigo de primera fila y un verdadero gestor dinámico de lo que podríamos considerar hitos relevantes de la propia historia de las relaciones internacionales de Chile como de su historia diplomática, a pesar de haberse alejado de ella durante los años de la dictadura militar. En todo caso esto no significó dejar de ser un diplomático ya que asumió

\footnotetext{
105 Ibídem.

106 Destacado pianista chileno galardonado internacionalmente. Desde 2007 profesor de piano en la Escuela Superior de Música de Detmold, Alemania.

107 Pianista chileno de carrera internacional radicado hace 20 años en Austria.

108 Cantante lirico chillanejo, parte del elenco de la Opera Nacional de Múnich.

109 Markwica, Robin. 2018. Emocional Choices. How the logic of affect shapes coercive diplomacy, p.25.
} 
tareas de alta responsabilidad en la ONU, algo que testimonia su prestigio en estos círculos internacionales.

Finalmente, es relevante constatar que James Holger Blair se yergue como una figura destacada dentro de la diplomacia chilena e internacional, su trayectoria permite acrisolar cómo Chile, un país en los bordes del sistema internacional, construyó y desarrolló sus lineamientos en política exterior durante los años del conflicto bipolar y cómo supo insertarse en un mundo en plena transformación internacional precisamente cuando retornaba a su vida democrática en los inicios de la década de los noventa.

\section{Referencias citadas}

\section{Fuentes Primarias}

Archivo General Histórico, Ministerio de Relaciones Exteriores (AGHMINREL), Santiago, 18 de abril de 1960, Fondo Histórico, Embajada chilena en Washington D.C, Estados Unidos, Vol. 5672, № 747/62.

Archivo General Histórico, Ministerio de Relaciones Exteriores (AGHMINREL), Santiago, 9 de enero de 1961, Fondo Organismos Internacionales, Organización de Naciones Unidas, delegación ante Naciones Unidas, Departamento Político “oficio confidencial № 23/2", Departamento Político, sesión 923.

Archivo General Histórico, Ministerio de Relaciones Exteriores (AGHMINREL), Santiago, 2 de abril de 1965, Fondo Países, Embajada de Chile en Moscú, Rusia, Vol. 198/ rus/1. confidencial 1.

Archivo General Histórico, Ministerio de Relaciones Exteriores (AGHMINREL), Santiago, 1 de diciembre de 1965, Fondo Países, Embajada de Chile en Moscú. Rusia, Vol. 198/ rus/1.

Archivo General Histórico, Ministerio de Relaciones Exteriores (AGHMINREL), Santiago, 8 de junio de 1965, Fondo Países, Embajada de Chile en Moscú, Rusia, Vol. 198/ rus/1, Confidencial № 10.

Archivo General Histórico, Ministerio de Relaciones Exteriores (AGHMINREL), Santiago, 6 de julio de 1965, Fondo Países, Embajada de Chile en Moscú, Rusia, Vol. 198/ rus/1. Confidencial № 17.

Archivo General Histórico, Ministerio de Relaciones Exteriores (AGHMINREL), Santiago, 18 de agosto de 1965, Fondo Países, Embajada de Chile en Moscú, Rusia, Vol. 198/ rus/1, Confidencial № 35.

Archivo General Histórico, Ministerio de Relaciones Exteriores (AGHMINREL), Santiago, 1 diciembre de 1965, Fondo Países, Embajada de Chile en Moscú, Rusia, Precalificación secretario Holger, Vol. 198/ rus $/ 1$.

Archivo General Histórico, Ministerio de Relaciones Exteriores (AGHMINREL), Santiago, 13 de febrero de 1969, Fondo Países, Embajada de Chile en Bonn, Convocatoria Asamblea Federal en Berlín. Aumentan tensión frente problema, GER, № 57.

Archivo General Histórico, Ministerio de Relaciones Exteriores (AGHMINREL), Santiago, 12 de febrero de 1969, Fondo Países, Embajada de Chile en Bonn, GER, № 57, Confidencial № 37/4.

Archivo General Histórico, Ministerio de Relaciones Exteriores (AGHMINREL), Santiago, 9 de abril de 1969, Fondo Países, Embajada de Chile en Bonn, Dialogo Moscú-Bonn a la luz confronta miento PekínMoscú, GER, № 57, Confidencial № 80/17. 
Archivo General Histórico, Ministerio de Relaciones Exteriores (AGHMINREL), Santiago, 6 de marzo de 1969, Fondo Países, Embajada de Chile en Bonn, Visita del Primer Ministro Wilson, GER, № 57, Confidencial № 54/10.

Archivo General Histórico, Ministerio de Relaciones Exteriores (AGHMINREL), Santiago, 28 de mayo de 1969, Fondo Países, Embajada de Chile en Bonn, GER, № 57, Confidencial № 124/23.

Archivo General Histórico, Ministerio de Relaciones Exteriores (AGHMINREL), Santiago, 15 de agosto de 1969, Fondo Países, Embajada de Chile en Bonn, GER, № 57, Confidencial № 183/38.

Archivo General Histórico, Ministerio de Relaciones Exteriores (AGHMINREL), Santiago, 10 de julio de 1969, Fondo Países, Embajada de Chile en Bonn, GER, № 57, Confidencial № 154/30.

Archivo General Histórico, Ministerio de Relaciones Exteriores (AGHMINREL), Santiago, 27 de diciembre de 1972, Fondo Organismos Internacionales, Delegación de Chile ante la Organización de las Naciones Unidas (NU), N.U, № 573, OIN № 2246/641.

Archivo General Histórico, Ministerio de Relaciones Exteriores (AGHMINREL), Santiago, 27 de diciembre de 1972, Fondo Organismos Internacionales, Delegación de Chile ante la Organización de las Naciones Unidas (NU), N.U, № 573, OIN № 2248/643.

Archivo General Histórico, Ministerio de Relaciones Exteriores (AGHMINREL), Santiago, 12 de diciembre de 1991, Gobierno de Chile, Embajada en Federación Rusa, Moscú, Télex Ordinario Urgente № 564.

Archivo General Histórico, Ministerio de Relaciones Exteriores (AGHMINREL), Santiago, 17 de diciembre de 1991, Gobierno de Chile, Embajada en Federación Rusa, "Declaraciones Canciller de Rusia sobre Caso Honecker", Télex Ordinario Urgente № 580.

Archivo General Histórico, Ministerio de Relaciones Exteriores (AGHMINREL), Santiago, 29 de abril de 1992, Gobierno de Chile, Embajada en Federación Rusa, Oficio Reservado № 004, Comprobante de Contabilidad № 229.

Archivo General Histórico, Ministerio de Relaciones Exteriores (AGHMINREL), Santiago, 8 de abril de 1992, Fondo James Holger, vol. 1, Télex secreto № 8.

Archivo General Histórico, Ministerio de Relaciones Exteriores (AGHMINREL), Santiago, 8 de abril de 1992, Fondo James Holger, vol. 1, Télex secreto № 11.

Archivo General Histórico, Ministerio de Relaciones Exteriores (AGHMINREL), Santiago, 8 de abril de 1992, Fondo James Holger, vol. 1, Télex secreto № 13.

Archivo General Histórico, Ministerio de Relaciones Exteriores (AGHMINREL), Santiago, 4 marzo de 1992, Fondo James Holger, vol. 1, Cable secreto № 4.

Archivo General Histórico, Ministerio de Relaciones Exteriores (AGHMINREL), Santiago, marzo, 1992, Fondo James Holger, vol. 1, Cable secreto № 6.

Archivo General Histórico, Ministerio de Relaciones Exteriores (AGHMINREL), Santiago, 31 de agosto de 1992, Fondo James Holger, Embajador James Holger al Ministro de Relaciones Exteriores de Chile, vol. 1, Télex secreto S/N.

Archivo Digital Patricio Aylwin (ADPA), 16 de diciembre de 1991, "Carta del presidente de la República de Chile Patricio Aylwin, al Canciller de la República Federal de Alemania, Helmut Kohl," CL CLUAH 1-722-6. 
Archivo Digital Patricio Aylwin (ADPA), 26 de noviembre de 1992, "Embajador alterno ante UN, CL CLUAH 1-109-5-1.

Archivo Digital Patricio Aylwin (ADPA), 22 de abril de 1992, "Entrevista al presidente de la República, Patricio Aylwin, en Diario 16 de España,", CL CLUAH 1-3-1-8.

Cámara de Diputados, 5 de agosto de 1992, "Carta del presidente de la Federación Rusa, Sr. Boris Yeltsin, al presidente Patricio Aylwin”, 22 de abril de 1992, Sesión 25a. Ordinaria, p. 2051.

"Ich bin im politischen Asyl", en Der Spiegel, Hamburg, N²3, 1991, pp. 37-45.

“Kein Herz für Honecker", en Der Spiegel, Hamburg, № 27, 1991, p. 17.

“Ein Prozeß ohne Ende?”, en Der Spiegel, Hamburg, N 51, 1991, pp. 18.-21.

"Holger, nuevo embajador en Moscú", en El Mercurio, Santiago, lunes 9 de septiembre de 1992, p. C6.

"Holger lleva instrucciones que Honecker deje embajada", en El Mercurio, Santiago, 10 de junio de 1992, p. A-12.

“Holger viaja a lograr que Honecker salga”, en La Nación, 10 de junio de 1992, p.7.

Memorias de Ministerio de Relaciones Exteriores de Chile, 1960. Primera parte, Departamento político, capítulo II, organismos y Conferencias Internacionales.

Memoria del Ministerio de Relaciones Exteriores, 1992. Primera parte, Departamento político, capítulo II, organismos y Conferencias Internacionales.

Naciones Unidas, A/C.5/45/SR.11, Summary record of the 11th meeting: 5th Committee, held on Wednesday, New York, General Assembly, 45th session, 17 October 1990.

Unidas, A/C.1/45/PV.18, Verbatim record of the 18th meeting: 1st Committee, held on Friday, New York, General Assembly, 45th session, 26 October 1990.

Naciones Unidas, A/C.2/45/SR.48, Summary record of the 48th meeting: 2nd Committee, held on Monday, New York, General Assembly, 45th session, 26 November 1990.

Naciones Unidas, A/C.1/45/PV.18, Summary record of the 15th meeting: Special Political Committee, held on Friday, New York, General Assembly, 46th session, 1 November 1991.

Naciones Unidas, A/46/PV.42, Provisional verbatim record of the 42nd meeting, held at Headquarters, New York, on Tuesday, 5 November 1991.

"Algunos pensaban que Honecker se suicidaría", Qué Pasa, 7 de noviembre de 2009. Disponible en: https://www.latercera.com/revista-que-pasa/17-1343-9-james-holger-algunos-pensaban-quehonecker-se-suicidaria/ (consultado el 27 de mayo 2021)

“Tendencias", en Revista Hoy, Santiago, 23 de marzo de 1992, pp.4-10.

"Sonderbotschafter Chiles verhandelt im Fall Honecker", Süddeutsche Zeitung, München, 17 de marzo de 1992.

"Chile schickt zweiten Honecker-Gesandten", Süddeutsche Zeitung, München, 19 de marzo de 1992. 


\section{Fuentes Secundarias}

Alija, Adela, Neila, José, Moreno, Antonio, Sáenz, José y Sanz, Carlos. 2018. Historia de las Relaciones Internacionales, Madrid, Alianza Editorial.

Alia, Francisco. 2017. Técnicas de investigación para historiadores. Las fuentes de la historia, Madrid. Editorial Síntesis.

Aróstegui, Julio. 1995. La investigación histórica. Teoría y Método, Barcelona, Crítica.

Armada de Chile. 2009. Almirantes de la República de Chile. 1810-2010, tomo I, 1810-1952, Valparaíso, Museo Naval y Marítimo.

Artaza, Mario, Ross, César (eds.). 2012. La política exterior de Chile, 1990-2009. Del aislamiento a la integridad global, Santiago, Ril editores.

Bange, Oliver. 2016. “Onto the Slippery Slope: East Germany and East-West Détente under Ulbricht and Honecker, 1965-1975”, en Journal of Cold War Studies, vol. 18, n³, Massachusetts, pp. 60-94.

Briggs, Asa y Clavin, Patricia. 1997. Historia contemporánea de Europa. 1789-1989, Barcelona, Editorial Crítica.

Brzezinski, Zbigniew. 1989. El gran fracaso: Nacimiento y muerte del comunismo en el siglo veinte, Buenos Aires, Javier Vergara Editor.

Bukovski, Vladimir. 1991. La Unión Soviética: de la utopía al desastre, Madrid, Arias Montano Editores.

Calvocoressi, Peter. 1999. Historia política del mundo contemporáneo. De 1945 a nuestros días, Madrid, Ediciones Akal.

Carrére D`Encausse, Hélène. 2016. Seis años que cambiaron el mundo. 1985.1991, Ariel, Barcelona.

Childs, David. 1969. "East Germany: Towards the twentieth anniversary", en The World Today, Vol. 25, $\mathrm{N}^{\circ} 10$, Londres, pp. 440-450.

Childs, David. 1997. "East German foreign policy: The search for recognition and stability", en International Journal, Vol. 32, $\mathrm{N}^{\circ} 2$, (spring), Londres, pp. $334-551$.

Daniels, Robert. 1993. The end of the communist revolution, London, Routledge.

Díez, José y Martín de la Guardia, Ricardo. 1998. Historia contemporánea de Alemania (1945-1995), Madrid, Editorial Síntesis.

Dosse, François. 2007. El arte de la biografía, México, Universidad Iberoamericana.

Duarte, Ángel, Ucelay, Enrique y Veiga Francisco. 2006. La paz simulada. Una Historia de la Guerra Fría, Madrid, Alianza Editorial.

Dufner, Georg (et. al.). 2016. Deutschland und Chile, 1850 bis zur Gegenwart: Ein Handbuch, Stuttgart, Heinz.

Fermandois, Joaquín. 1985. Chile y el Mundo. 1970-1973. La política exterior del Gobierno de la Unidad Popular y el Sistema Internacional, Santiago, Ed. Universidad Católica de Chile.

Gajardo, Gustavo y Medina, Cristian. 2019. “De la amistad a la Diplomacia. El reconocimiento internacional del Gobierno de la Unidad Popular a la República Democrática Alemana, 1971", en Revista Izquierdas, № 48, Santiago, pp. 1468-1492. 
Gallego, Henar y Bolufer, Mónica (ed). (2016). ¿Y ahora qué? Nuevos usos del género biográfico, Barcelona, Icaria.

Götz, Shirley. 2015. Liderazgo y política exterior, Santiago, Ril editores.

Gray, William. 2003. Germany's Cold War: The global campaign to isolate East Germany 1949 - 1969, Chapel Hill, The University of North Carolina Press.

Grant, Susan-Mary. 2014. Historia de Estados Unidos de América, España, Akal Ediciones.

Guevara, Leticia, Feliú, Fernando. 2011. Participación de Chile en operaciones de paz de Naciones Unidas: Misión Haití y análisis del nuevo marco jurídico nacional, Facultad de Derecho, Departamento de Derecho Internacional, Universidad de Chile, Tesis para optar al grado de Licenciado en Ciencias Jurídicas y Sociales.

lacobelli, Pedro, Robert Cribb, Juan Luis Perello (eds.). 2018. Asia y el Pacífico durante los años de la Guerra Fría, Santiago, Fondo de Cultura Económica.

Jovitt, Ken. 1992. New World Disorder. The leninist extinction, Berkeley, University of California Press.

Judt, Tony. 2006. Postguerra. Una historia de Europa desde 1945, Madrid, Taurus.

Kramer, Mark. 2003. "Special Issue: The Collapse of the Soviet Union (Part 2): Introduction", en Journal of Cold War Studies, vol. 5, Massachusetts, $N^{\circ} 4$, pp. 3-42.

Lagos, Jaime. 2008. Al servicio de Chile. Crónicas de un diplomático, Santiago, Ediciones Universidad Fines Terrae.

Magasich, Jorge. 2013. "La política internacional chilena del gobierno de la Unidad Popular 1970 - 1973 : Un intento de pluralismo en las Relaciones Internacionales", en Tiempo Histórico, № 7, Santiago, pp. 15-27.

Martín de la Guardia, Ricardo y Pérez Sánchez, Guillermo. 2001. Historia de la integración europea, Barcelona, Ariel Estudios Europeos.

Martín de la Guardia, Ricardo, Pérez, Guillermo. 1995. La Unión Soviética: de la perestroika a la desintegración, Madrid, Itsmo.

Martín de la Guardia, Ricardo, Pérez, Guillermo. 1993. El sueño quedó lejos. Crisis y cambios en el mundo actual, Valladolid, Secretariado de Publicaciones, UVA.

Martín de la Guardia, Ricardo. 2012. 1989, el año que cambió el mundo. Los orígenes del orden internacional después de la Guerra Fría, Madrid, Akal.

Markwica, Robin. 2018. Emocional Choices. How the logic of affect shapes coercive diplomacy, Oxford, Oxford University Press.

Medina, Cristián, Gajardo, Gustavo. 2017. "The fissures of the "curtain of steel" from Chile. Poland 1956", en Almanaque histórico latinoamericano, N²18, Moscú, pp. 220-242.

Medina, Cristian, Gajardo, Gustavo. 2016. "Entre protectores y opositores: Labor política frente al caso Honecker”, en Revista de Ciencia Política, Vol. 36, № 3, Santiago, pp. 731-748.

Medina, Cristian, Gajardo, Gustavo. 2017. “De apátrida errante a vecino santiaguino. El “caso Honecker" desde las fuentes oficiales (1991-1994)", en Tzintzun Revista de Estudios Históricos, № 65, Morelia, pp. 260-284. 
Medina, Cristian, Gajardo, Gustavo. 2019. "Chile y el amigo alemán. El "caso Honecker". 1991-1994: tensión internacional en la temprana posguerra fría", en Cuadernos de Historia, № 50, Santiago, pp. 135-168.

Medina, Cristian (et.al). 2018. "El huésped (in)esperado. Erich Honecker en la embajada de Chile en Moscú" en Lilón, Domingo y Deák, Máté, Encuentros. Europa-Iberoamérica en un mundo globalizado, Hungría, Centro iberoamericano Universidad de Pécs.

Merle, Marcel. 1991. Sociología de las Relaciones Internacionales, 2a. edición, Madrid, Alianza.

Pacheco, Máximo, Holger, James. 2009. Recuerdos de la Unión Soviética, Santiago, Editorial Andrés Bello.

Pani, Erika. 2016. Historia mínima de Estados Unidos de América, Madrid, Turner Publicaciones.

Pappe, Ilan. 2007. Historia de la Palestina moderna. Un territorio, dos pueblos, Madrid, Ediciones Akal S.A.

Pereira, Juan Carlos (Coord.). 2001. Historia de las relaciones internacionales contemporáneas, Barcelona, Editorial Ariel S.A.

Pedemonte, Rafael. 2018. "Desafiando la bipolaridad: la independencia diplomática del gobierno democratacristiano en Chile y su acercamiento con el "mundo socialista" (1964-1970)", en Estudo Ibero-Americanos, vol 44, № 1, Porto Alegre, pp. 186-199.

Pedemonte, Rafael. 2019. "A Case of "New Soviet Internationalism": Relations between the USSR and Chile's Christian Democratic Government, 1964-1970”, en Journal of Cold War Studies, vol. 21, № 3, Massachusetts, pp. 4-25.

Poch de Feliú, Rafael. 2003. La gran transición. Rusia, 1985-2002, Barcelona, Crítica.

Quezada, Abraham. 2009. "Neruda - Nueva York - Naciones Unidas", en Revista Diplomacia, Academia Diplomática de Chile, N¹19, Santiago, pp. 89-92.

VV.AA. 2014. "Los retos de la biografía (dossier)", en Revista Ayer, 1, Madrid, Asociación de Historia Contemporánea, pp. 13-135.

Ross, César. 2014. "Hernán Santa Cruz: del pensamiento a la acción”, en Horizontes Latinoamericanos, Vol.1, N², Recife, pp. 79-92.

S/A. 2012. "Entrevista al académico de número, Máximo Pacheco Gómez", en Societas, Academia Chilena de Ciencias Sociales, Políticas y Morales, N¹4, Santiago, pp. 90-93.

Sarotte, Mary-Elise. 2001. Dealing with the Devil: East Germany, Détente, and Ostpolitik, 1969 - 1973, Chapel Hill, University of North Carolina Press.

Service, Robert. 2000. Historia de Rusia en el siglo XX, Barcelona, Editorial Crítica.

Taibo, Carlos. 1991. Unión Soviética. La quiebra de un modelo, Madrid, Los Libros de la Catarata.

Truyol, Antonio. 1973. La teoría de las relaciones internacionales como sociología, Madrid, Ediciones Internacionales.

Ulloa, Erna. 2013. Chile ante el Consejo de Seguridad de Naciones Unidas. Acción Diplomática y Opinión Pública 1952-2004. Universidad de Valladolid, España, Tesis doctoral. 
Ulloa, Erna, Medina, Cristián. 2019, "Outline of a diplomatic leader in the international community: Hernán Santa Cruz and his works at the United Nations", en Human Rights Quaterly, N41, Maryland, pp. 962-981.

Werner Kilian, 2001. Die Hallstein-Doktrin. Der diplomatische Krieg zwischen der BRD und der DDR 19551973: Aus den Akten der beiden deutschen Aussenministerien, Berlín, Dunker \& Humblot.

Zorgbibe, Charles. 1997. Historia de las relaciones internacionales. Del sistema de Yalta a nuestros días, Madrid, Alianza Editorial.

\section{Enlaces web}

Ministerio de Relaciones Exteriores, 04 de agosto 2014, Sala de Prensa, "Cancillería lamenta el fallecimiento de Embajador James Holger Blair". Disponible en: https://www.minrel.gob.cl/cancilleria-lamenta-el-fallecimiento-de-embajador-james-holgerblair/minrel_old/2014-08-04/175919.html (consultado el 27 de mayo de 2021)

Armada de Chile, 29 de enero de 2021, Nota de prensa, "Parte a misión de paz en Chipre nuevo contingente de la Armada", sin autor. Disponible en: https://www.armada.cl/armada/noticiasnavales/parte-a-mision-de-paz-en-chipre-nuevo-contingente-de-la-armada/2021-01-

29/180015.html (consultado el 27 de mayo de 2021) 